\title{
Effect of wavelength, deposition temperature and substrate type on cobalt ferrite thin films grown by pulsed laser deposition
}

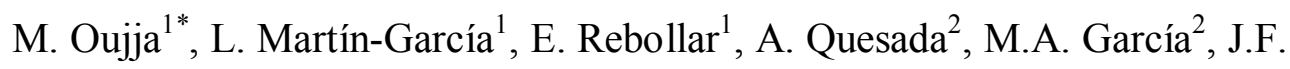 \\ Fernández $^{2}$, J.F. Marco ${ }^{1}$, J. de la Figuera ${ }^{1}$, M. Castillejo ${ }^{1}$ \\ ${ }^{1}$ Instituto de Química Física “Rocasolano”, CSIC, 28006 Madrid, Spain \\ ${ }^{2}$ Instituto de Cerámica y Vidrio, CSIC, 28049 Madrid, Spain \\ *corresponding author:m.oujja@iqfr.csic.es
}

\begin{abstract}
In pulsed laser deposition, the laser irradiation wavelength and the substrate nature and temperature crucially affect the composition, crystallinity, structure and magnetic properties of the grown deposits. In this work, cobalt ferrite $\left(\mathrm{CoFe}_{2} \mathrm{O}_{4}\right)$ thin films were deposited on $\mathrm{Si}(100)$ and $\mathrm{SrTiO}_{3}(100)$ single crystal substrates at room temperature and $770 \mathrm{~K}$ using laser wavelengths of 213, 532 and $1064 \mathrm{~nm}$. The deposited films were characterized by atomic force microscopy to determine the surface morphology, by Xray diffraction to examine their crystallinity, and by micro-Raman, scanning electron microscopy/energy-dispersive X-ray spectroscopy, X-ray photoelectron and Mössbauer spectroscopies to investigate their composition and stoichiometry. Magnetic characterization was carried out by superconducting quantum interference device magnetometry. At $770 \mathrm{~K}$ and $1064 \mathrm{~nm}$, the films consisted of single-crystal $\mathrm{CoFe}_{2} \mathrm{O}_{4}$ ((100) orientation) when grown on $\mathrm{SrTiO}_{3}$, and of polycrystalline $\mathrm{CoFe}_{2} \mathrm{O}_{4}$ when grown on $\mathrm{Si}$. The composition of the films became more complex at shorter wavelengths as they contained magnetite and other minority phases in different concentrations. The crystalline quality of the films also decreased with decreasing wavelength even including superparamagnetic species. In general, for the same wavelength, the deposits
\end{abstract}


obtained at room temperature were less crystalline than those produced with the substrate heated at $770 \mathrm{~K}$.

\section{Keywords}

Spinel oxides, Cobalt ferrite, Pulsed laser deposition, Thin films 


\section{Introduction}

Spinel ferrites are receiving increasing interest due to their magnetic properties and also due to their potential in various applications such as spin filters, resistive switching, magnetoelectric coupling, microwave absorption and hyperthermia [1-6]. Ferrites offer the advantage of having the optical bandgap in the region of visible light. Cobalt ferrite, $\mathrm{CoFe}_{2} \mathrm{O}_{4}$ (CFO), is a semiconductor ferrite with direct and indirect energy gaps of 2.74 and $1.18 \mathrm{eV}$, respectively [7]. CFO is an inverse spinel ferrite particularly interesting due to its high Curie temperature [8], large magnetostriction coefficient $[9,10]$ and moderate saturation magnetization [11]. $\mathrm{CFO}$, with general formula $\mathrm{AB}_{2} \mathrm{O}_{4}(\mathrm{~A}=\mathrm{Fe}$ and $\mathrm{B}=\mathrm{Co}, \mathrm{Fe}$ ), is a cubic ferrite where half of the $\mathrm{Fe}^{3+}$ ions occupy the octahedral sites and the remaining half go into the tetrahedral sites, whereas $\mathrm{Co}^{2+}$ ions are located at the octahedral sites.

The magnetic properties of CFO nanoparticles are strongly size dependent. Under the critical diameter limit $(\approx 40 \mathrm{~nm})$ for the single domain regime [12], both coercivity and magnetization decrease with decreasing nanoparticle size [13]. The decrease of magnetization with the size of the nanoparticles in the single domain region is mainly due to the canting of the spins on the surface of the nanoparticles [14]. Also, the continuous decrease of coercivity with size eventually leads to a superparamagnetic state of the single domain nanoparticles, which is useful for many biomedical applications $[15,16]$. In contrast, single domain nanoparticles with high coercivity are required for high density data storage applications. Therefore, there is a lot of interest in tuning the magnetic properties of single domain CFO nanoparticles to make them useful for different applications. Some groups have reported on the tuneable magnetic properties of $\mathrm{CFO}$ thin films by controlling their microstructure, grain size, film 
thickness, choice of substrate, and lattice strain [17-19]. Several thin film deposition techniques, such as molecular beam epitaxy [19], pulsed laser deposition (PLD) [20], sputtering [21], ion-beam deposition [22], and sol-gel processing [23,24], have been used over the years to prepare CFO thin films. Among them, PLD has been the most versatile in terms of $\mathrm{CFO}$ thin film growth because of its relatively low substrate temperature requirements [25] as compared to the high annealing temperatures in sol-gel processes $[23,24]$ and the precise control of film crystallinity, either polycrystalline [26] or epitaxial [18], and thickness [17] that otherwise affect the magnetic anisotropy [27,28] and residual strain [29] in CFO thin films. The most promising technique to deposit epitaxial thin films with a preferential crystallographic direction, uniform chemical distribution and perpendicular magnetic anisotropy was found to be PLD $[28,30]$.

PLD offers the possibility to control the size, shape and crystalline phase of the nanodeposits by varying the laser and other growth parameters [31-33]. In particular, the effect of wavelength on the formation of nanostructured films produced by PLD has been studied in a very diverse range of materials and an increase of the nanoparticle mean diameter with wavelength has been reported [31-36].

$\mathrm{CoFe}_{2} \mathrm{O}_{4}$ presents very attractive properties to be exploited in nanotechnology by the synthesis of the material in the nanoscale domain while maintaining the original bulk properties. However, the attempts to use the potential of cobalt ferrite in thin films have led to disappointing results [37,38]. At the thin film limit, the role of the surface becomes more relevant and thus, careful attention must be paid to the effect of the structural defects or surface roughness as it might dominate over the intrinsic properties of the material. The successful integration of cobalt ferrite and other materials into devices comes from the control of the growth process. Only by the synthesis of 
structurally and compositionally perfect thin films, substantial progress in nanotechnological applications of CFO will be achieved.

The present work is devoted to study the effect of laser wavelength, type and temperature substrate on the composition, crystallinity, structure and magnetic properties of the grown thin films by PLD from CFO targets. We report results obtained at the wavelengths of 213, 532 and $1064 \mathrm{~nm}$ on $\mathrm{Si}$ (100) and $\mathrm{SrTiO}_{3}$ (STO) (100) substrates at temperatures of 300 and $770 \mathrm{~K}$ from self-prepared sintered cobalt ferrite targets. For this purpose we compared deposits grown under the same conditions of ambient pressure, deposition time, laser spot size on the target surface and irradiation fluence values of 8 times the ablation threshold fluence for each wavelength. The characterization of the deposited films was carried out by atomic force microscopy to determine the surface morphology, by X-ray diffraction to examine their crystallinity, and by micro-Raman, scanning electron microscopy/energy-dispersive X-ray spectroscopy, X-ray photoelectron and Mössbauer spectroscopies to investigate their composition and stoichiometry. Magnetic characterization was carried out by superconducting quantum interference device magnetometry. The deposits were found stoichiometric for all laser wavelengths, type of substrate and temperature. At $770 \mathrm{~K}$, the films were found crystalline and single-phase (100) with cubic spinel structure when grown on STO, and polycrystalline when grown on Si. Differently, at room temperature the deposits, although crystalline, also display amorphous domains.

\section{Experimental}

The cobalt ferrite targets used in this study were synthesized following a sol-gel process using Fe and $\mathrm{Co}$ nitrates with formulas $\mathrm{Co}\left(\mathrm{NO}_{3}\right)_{2} \cdot 6 \mathrm{H}_{2} \mathrm{O}$ and $\mathrm{Fe}\left(\mathrm{NO}_{3}\right)_{2} \cdot 9 \mathrm{H}_{2} \mathrm{O}$. The 
nitrates were dissolved in stoichiometric ratio 1:2 in deionized water. Citric acid was subsequently added to the solution, which was then stirred at $333 \mathrm{~K}$ for $1 \mathrm{~h}$. The gel was dried in a hot air oven for $24 \mathrm{~h}$. The precursor obtained was calcined for $1 \mathrm{~h}$ at $673 \mathrm{~K}$. The obtained powders were sieved $\leq 63 \mu \mathrm{m}$ and cold-uniaxially pressed at $55 \mathrm{MPa}$ into disks of $15 \mathrm{~mm}$ of diameter and $2 \mathrm{~mm}$ of thickness. The targets were finally sintered in air at $1473 \mathrm{~K}$ for $2 \mathrm{~h}$, employing a $5 \mathrm{~K} / \mathrm{min}$ annealing rate. Although the microstructure of the target was not characterized in this work, it is assumed that the grain size is determined by the diameter of the holes of the sieve employed, and given that the sintering temperature does not significantly activate grain growth [39], and therefore it is equal or below $63 \mu \mathrm{m}$. The targets consist of a dominant CFO phase as determined by XRD and Mössbauer spectroscopy, and reported in [40].

The deposits were grown in a PLD system consisting of a stainless-steel vacuum chamber pumped down to $2 \times 10^{-4} \mathrm{~Pa}$ by a turbo-molecular pump [41]. The targets were placed on a rotating sample holder and ablated with a Q-switched Nd:YAG laser (FWHM $15 \mathrm{~ns}, 10 \mathrm{~Hz}$ ) at the excitation wavelengths of 213, 532 and $1064 \mathrm{~nm}$. The laser beam was focused onto the target at $45^{\circ}$ to a spot area of $0.14 \mathrm{~mm}^{2}$ (elliptic spot with $0.6 \times 0.3 \mathrm{~mm}$ in diameter, significantly higher than the CFO grain size). The corresponding threshold fluences were determined by measuring the minimum single pulse energy necessary to yield a luminous plume as detected by eye and the diameter of the irradiated region by the print left on an unplasticized polyvinyl chloride sheet. For each wavelength, the fluence (laser pulse energy per unit area) used for fabrication of deposits was fixed to a value corresponding to 8 times the ablation threshold at this particular wavelength, following the method considered in previous PLD studies with hematite targets [42]. The fluence values applied were $0.8,2.4$ and $4 \mathrm{~J} \mathrm{~cm}^{-2}$ for 213 , 532 and $1064 \mathrm{~nm}$, respectively. Substrates of $10 \mathrm{~mm} \times 10 \mathrm{~mm}$ size, of SrTiO3 (100) 
from Crystek and Si (100) were used for film growth. The STO (100) substrates were used as received from the manufacturer. In turn, Si (100) substrates were ultrasonically degreased in acetone and methanol for $10 \mathrm{~min}$. The substrates were mounted on a heating element that allows operation in a temperature range between 300 and $770 \mathrm{~K}$, as measured by a thermocouple. They were placed in front of the cobalt ferrite target at a distance of $40 \mathrm{~mm}$. Deposits were grown by delivering 144.000 pulses to the target (resulting in a deposition time of around $4 \mathrm{~h}$ ).

The morphology of the deposits was examined by AFM (Multimode 8, Bruker) in tapping mode and by scanning electron microscopy/energy-dispersive X-ray (SEM, Philips XL30). The AFM images were analyzed with the Nanoscope Analysis 1.40 software. The mean roughness $\left(\mathrm{R}_{\mathrm{a}}\right)$, determined from AFM analysis, is the arithmetic average of the deviations in height from the center plane of the sample and corresponds to the average of 5 independent measurements in different locations of the sample. The thickness values result also from the average of 5 different measurements in different film edges on the STO and Si substrates.

The crystalline quality and composition of the deposits was characterized by Xray diffraction (XRD, Philips XPert) using $\mathrm{Cu} \mathrm{K}_{\alpha}(1.54 \AA)$ radiation in the $\theta / 2 \theta$ configuration. Analysis by micro-Raman spectroscopy was carried out with a Renishaw InVia 0310-02 system equipped with a Leica micro-scope and an electrically refrigerated $\mathrm{CCD}$ camera under continuous $\mathrm{Nd}$ :YAG laser excitation at $532 \mathrm{~nm}$. Low laser power outputs, in the range of $0.15-0.3 \mathrm{~mW}$, were used to prevent damage of the samples. Spectral acquisition was performed at room temperature using a focused beam on a randomly oriented sample. The diameter of the laser spot on the sample was diffraction limited by the objective lens $(\times 50)$ and calculated to be $1 \mu \mathrm{m}$. For each spectrum, 10 scans were collected and summed up over the $200-800 \mathrm{~cm}^{-1}$ Raman shift 
range to provide good signal to noise ratios. The wavenumber resolution and acquisition time were $2 \mathrm{~cm}^{-1}$ and $10 \mathrm{~s}$ respectively.

${ }^{57} \mathrm{Fe}$ Mössbauer spectra were recorded in constant acceleration mode with a ca. $25 \mathrm{mCi}{ }^{57} \mathrm{Co} / \mathrm{Rh}$ source in conventional constant acceleration spectrometer. Integral Conversion Electron Mössbauer Spectroscopy (ICEMS) data were acquired at room temperature using a parallel plate avalanche counter [43]. All the spectra were computer-fitted and the chemical isomer shift data are quoted relative to metallic iron at room temperature. X-ray photoelectron spectroscopy (XPS) data were acquired using Al $\mathrm{K} \alpha$ radiation $(\mathrm{h} v=1486.6 \mathrm{eV})$. The reported spectra were recorded at an electron takeoff angle of $90^{\circ}$ (unless explicitly mentioned) with a constant analyzer pass energy of 20 $\mathrm{eV}$. The binding energy scale was referenced to the binding energy of the $\mathrm{C} 1 \mathrm{~s}$ signal of the adventitious carbon layer which was set at $284.6 \mathrm{eV}$. The spectra were fitted with pseudo Voigt line profiles and a Shirley background using the CasaXPS software (version 2.3.16). The Lorentzian/Gaussian mixing ratio and FWHM were fixed along the series of spectra. Magnetization curves at $10 \mathrm{~K}$ and $300 \mathrm{~K}$ were recorded using a Magnetic Properties Measurement System (MPMS XL) from Quantum Design with applied magnetic field in the plane of the films with values up to $50 \mathrm{kOe}$.

\section{Results}

\subsection{Surface crystallinity}

The crystalline quality and composition of the CFO deposits were characterized by XRD. Figure 1 presents XRD patterns of samples grown on Si (100) substrates at different irradiation wavelengths and substrate temperatures. The XRD peaks obtained from deposits at $770 \mathrm{~K}$ upon irradiation at $1064 \mathrm{~nm}$ (Fig. 1a) located at $30.1^{\circ}, 35.4^{\circ}$, 
$37.1^{\circ}, 43.1^{\circ}, 53.4^{\circ}, 57^{\circ}, 62.6^{\circ}$ and $79.2^{\circ}$ are assigned to $\mathrm{CoFe}_{2} \mathrm{O}_{4}(220),(311),(222)$, (400), (422), (511), (440) and (444), respectively. This pattern reveals the polycrystalline character of the deposited cobalt ferrite films (Joint Committee on Powder Diffraction Standards Card No. 01-079-1744). The peaks centered at $33.1^{\circ}$ and $69.2^{\circ}$ correspond to the $\mathrm{Si}$ substrate diffractions. The silicon lattice parameter is far from that of CFO and thus on this substrate type it is very hard to obtain an epitaxial CFO film. The XRD patterns of the samples grown at $532 \mathrm{~nm}$ and $770 \mathrm{~K}$ (Fig. 1b) are quite similar to those obtained at $1064 \mathrm{~nm}$ with an appreciable broadening of the (400) diffraction peak at $43.1^{\circ}$ and a high decrease in the peak intensity indicative of the presence of amorphous domains. For deposits fabricated at $213 \mathrm{~nm}$ and $770 \mathrm{~K}$, the XRD pattern (Fig. 1c) presents a noisy, weak signal without any clear structure, except for the dominant peaks of the $\mathrm{Si}$ substrate. In general, for any deposition wavelength, the $\mathrm{Si}$ peaks are the most intense ones in the XRD patterns, indicating that the grown films must be quite thin, particularly those deposited with shorter wavelengths (see Section 3.3. below).

The PLD deposits obtained by irradiation at $1064 \mathrm{~nm}$ on silicon substrates at room temperature (Fig. 1d) present an XRD pattern similar to those grown with the substrate heated at $770 \mathrm{~K}$, although the appreciable broadening of the XRD peaks is indicative of a large contribution of amorphous or small particle domains. No XRD peaks were obtained upon irradiation at 532 and $213 \mathrm{~nm}$ on room temperature $\mathrm{Si}$ substrates (Figs. 1e and 1f).

The XRD patterns of the deposits on STO substrates are shown in Figure 2. All obtained films were epitaxial and monocrystalline, displaying a single peak at $43.1^{\circ}$ that corresponds to the CFO (400) diffraction plane. Similarly, as for the case of the Si substrate, the XRD peaks corresponding to room temperature STO (Figs. 2d and 2e) 
are broader than those obtained with the substrate heated at $770 \mathrm{~K}$ (Figs. 2 a-c), indicating that formation of amorphous/small particle domains is promoted at room temperature. All other observed peaks correspond to the STO (100) substrate, as indicated. No peaks were observed for films obtained by ablation at 213 on room temperature STO (Fig. 2f), except for those of STO. This again is indicative of the formation of very thin films (see Section 3.3. below).

The average crystalline domain size of the deposits, $D$, can be estimated using the Scherrer law, $D=0.9 \lambda / B \cos \theta_{B}$, where $\lambda$ is the $\mathrm{X}$-ray wavelength $(\mathrm{Cu} \mathrm{K} \alpha=0.154$ $\mathrm{nm}$ ) and $B$ the full width at half-maximum (in radians) of the diffraction peak. The Scherrer law does not include peak broadening due to stress/strain, which is important in the case of thin films, and therefore the calculated crystalline domain sizes may be over/subestimated. Nevertheless, the obtained values can be used to assess the influence of deposition conditions on the crystallinity of the deposits. The calculated nanocrystalline domain sizes are collected in Table 1, showing larger size at longer laser wavelength and higher substrate temperature.

\subsection{Micro-Raman Spectroscopy}

Micro-Raman spectra of the deposits were recorded to check the phase purity. The results are shown in Figures 3 and 4. The micro-Raman spectra of deposits on Si (100) at room temperature and $770 \mathrm{~K}$ (Figure 3), grown by irradiation at 1064 and $532 \mathrm{~nm}$, include bands at 207, 303, 470, 572, 616 and $690 \mathrm{~cm}^{-1}$ which are characteristic of cobalt ferrite. No Raman bands were observed for deposits at $213 \mathrm{~nm}$ because, as indicated above, they are extremely thin. The same Raman bands were observed for the deposits obtained by irradiation at $1064 \mathrm{~nm}$ on STO (100) at room temperature and $770 \mathrm{~K}$ (Fig. 
4). On this substrate, the absence of Raman bands of films obtained at 532 and $213 \mathrm{~nm}$ at the two substrate temperatures (spectra not shown) is due again to the small amount of deposited material.

The two main peaks at 470 and $690 \mathrm{~cm}^{-1}$ observed in the spectra of CFO are assigned to octahedral site ( $O$-site) sub-lattice and tetrahedral site ( $T$-site) sub-lattice vibration modes, respectively, and reflect the local lattice effects in the tetrahedral and octahedral sub-lattices. It is well known that the spinel structure is assigned with the $\mathrm{A}_{1 \mathrm{~g}}$ $(\mathrm{R})+\mathrm{E}_{\mathrm{g}}(\mathrm{R})+\mathrm{T}_{1 \mathrm{~g}}+3 \mathrm{~T}_{2 \mathrm{~g}}(\mathrm{R})+2 \mathrm{~A}_{2 \mathrm{u}}+2 \mathrm{E}_{\mathrm{u}}+4 \mathrm{~T}_{1 \mathrm{u}}(\mathrm{IR})+2 \mathrm{~T}_{2 \mathrm{u}}$ phonon modes [44]. Out of these phonon modes, five are Raman active, namely $A_{1 g}, E_{g}$ and $3 \mathrm{~T}_{2 \mathrm{~g}}$. In the obtained spectra the Raman modes above $600 \mathrm{~cm}^{-1}$ (616 and $690 \mathrm{~cm}^{-1}$ ) correspond to the symmetric stretching of the oxygen atom with respect to the metal-ion in tetrahedral void, tetrahedral breath mode and are assigned as $\mathrm{A}_{1 \mathrm{~g}}$. The other frequency modes below $600 \mathrm{~cm}^{-1}\left(207,303,470\right.$ and $\left.572 \mathrm{~cm}^{-1}\right)$ correspond to the symmetric and antisymmetric bending of the oxygen atom in metal-ion (M-O) bonds at the octahedral voids and are assigned as $\mathrm{E}_{\mathrm{g}}$ and $3 \mathrm{~T}_{2 \mathrm{~g}}$ [44]. In order to estimate the $\mathrm{Co}^{2+}$ ions ratio at the tetrahedral/octahedral sites, we calculated the intensity ratio of the corresponding peaks at $616 \mathrm{~cm}^{-1}$ [44] and $470 \mathrm{~cm}^{-1}$ [45]. As observed in Figures 3 and 4, the peak intensity ratio drops with increasing substrate temperature indicating that substrate heating promotes a larger inversion degree in the CFO spinel-related structure of deposits (i.e. more $\mathrm{Co}^{2+}$ ions sitting on the octahedral positions).

\subsection{Surface morphology}


The topography of the films was studied by AFM and SEM/EDX. The thickness and the Fe/Co content ratio were estimated using AFM and SEM/EDX, respectively. The values of thickness, roughness and Fe/Co ratio of the deposits are presented in Table 2.

Figures 5 and 6 show the AFM micrographs of the deposited CFO films. In some cases, the surface presents a distinctive morphology with a background roughness in the nanometer range on top of which nanometric mounds are oriented along the (110) substrate direction. The grain size of the CFO films increased with both increasing deposition temperature and laser irradiation wavelength.

For the films deposited on Si (100) at $770 \mathrm{~K}$ by irradiation at 1064 and $532 \mathrm{~nm}$ (Figs. 5 a, b), the nanostructures appear as a mixture of cubic and orthogonal prisms with straight edges, with face dimensions around 50 and $150 \mathrm{~nm}$, respectively. Upon irradiation at $213 \mathrm{~nm}($ Fig. 5c) the deposits are constituted by round nanoparticles with sizes of few tens of nanometers.

Figures 5 d-f display AFM height images of the deposits obtained by irradiation at 1064,532 and $213 \mathrm{~nm}$ and substrate temperature of $300 \mathrm{~K}$. In this case, and in contrast with the results obtained at $770 \mathrm{~K}$, the deposits contain round nanoparticles with sizes of few tens of nanometers with some larger aggregates of up to $200 \mathrm{~nm}$. The size of nanoparticles increases with increasing the irradiation wavelength.

Figures 6 a-f show the CFO deposits on STO (100) substrates at 770 and $300 \mathrm{~K}$ upon irradiation at 1064, 532 and $213 \mathrm{~nm}$. The AFM height images also present a distinctive morphology with nanometric square shape islands oriented along (110) substrate direction over a background of nanometer range roughness. Deposits at 213 $\mathrm{nm}, 770 \mathrm{~K}$ constitute an exception as they consist of rectangular nanometric structures with dimensions of some tens of nanometers. This fact could be due to the small amount of deposited material ( $5 \mathrm{~nm}$ thickness) and to the effect of high deposition temperature. 
The different contrast observed in SEM images between background round nanoparticles and the square shape islands (Figures not shown) suggests that they have different composition. The size of the background round nanoparticles depends on the irradiation wavelength and the substrate temperature, as observed for the Si substrate.

For a fixed time deposition (4 hours) and irradiation fluence ( 8 times the ablation threshold), the AFM and SEM/EDX results herein indicate that the laser wavelength and substrate type and temperature exert a strong influence on the morphology and dimensions of the nanostructured films produced by ns PLD from CFO targets (Table 2).

Deposits on Si are thicker at $770 \mathrm{~K}$ than those obtained at room temperature, however on STO the effect of temperature is less marked. On Si (100), the differences observed are related to the film morphologies, where well-defined CFO crystallites characterize the films formed at $770 \mathrm{~K}$ (Fig. 5a), as compared to the smooth thin film obtained at $300 \mathrm{~K}$ (Fig. 5d). However, on STO, the good crystalline network matching between substrate and deposited material, favours the formation of highly ordered epitaxial growth of CFO films, and in this case the increase of temperature is less crucial than in the case of $\mathrm{Si}$.

The Fe/Co ratios for the different CFO thin films obtained by EDX and collected in Table 2 are all lower than the expected 2.0 stoichiometric ratio. This would suggest that there is loss of iron during pulsed laser deposition. However, we would like to point out that the strong overlap between the $\mathrm{Co} \mathrm{K} \alpha$ line at $6930 \mathrm{eV}$ and the $\mathrm{Fe} \mathrm{K} \beta$ line at $7058 \mathrm{eV}$ in the EDX spectra precludes a rigorous determination of the Co concentration and can lead to its overestimation (in fact, we obtained a Fe/Co ratio of 1.8 for the target, a value smaller than the theoretically expected). Therefore, more than loss of 
iron/enrichment in $\mathrm{Co}$, the low $\mathrm{Fe} / \mathrm{Co}$ values obtained are due to the inaccuracy of the EDX method to calculate this particular atomic ratio.

\subsection{Integral conversion electron Mössbauer spectroscopy (ICEMS) and X-ray photoelectron spectroscopy (XPS)}

Figure 7 shows the ICEMS spectra recorded from the CFO films deposited on $\mathrm{Si}$ substrates at $770 \mathrm{~K}$ and $300 \mathrm{~K}$ at the three irradiation wavelengths of 1064, 532 and 213 $\mathrm{nm}$.

The spectrum of the sample deposited at $770 \mathrm{~K}$ by irradiation at $1064 \mathrm{~nm}$ (Fig. 7a) is, except by a very minor $(<1 \%)$ paramagnetic component, very similar to that recorded from the $\mathrm{CoFe}_{2} \mathrm{O}_{4}$ target [41], both in terms of the Mössbauer parameters and relative areas of the two sextets observed $\left(\delta_{\mathrm{A}}=0.28 \mathrm{mms}^{-1}, 2 \varepsilon_{\mathrm{A}}=-0.01 \mathrm{mms}^{-1}, \mathrm{H}_{\mathrm{A}}=49.3\right.$ $\mathrm{T}$, Area $_{\mathrm{A}}=72 \% ; \delta_{\mathrm{B}}=0.40 \mathrm{mms}^{-1}, 2 \varepsilon_{\mathrm{B}}=0.02 \mathrm{mms}^{-1}, \mathrm{H}_{\mathrm{B}}=51.8 \mathrm{~T}$, Area $\left._{\mathrm{B}}=27 \%\right)$. The Mössbauer data indicate that the deposited film reproduces the composition of the target and, therefore, corresponds to a genuine $\mathrm{CoFe}_{2} \mathrm{O}_{4}$ spinel phase.

The spectra recorded from the films deposited at $770 \mathrm{~K}$ and at the irradiation wavelengths of 532 and $213 \mathrm{~nm}$ present a more complex pattern (Figs. $7 \mathbf{b}$, c): in general they show broader lines than the spectra of the film produced at $1064 \mathrm{~nm}$ as well as additional components. They contain a broad third magnetic sextet with an isomer shift, $\delta=0.44-0.60 \mathrm{mms}^{-1}$, and a hyperfine magnetic field, $\mathrm{H}$, around $45.0 \mathrm{~T}$. These values resemble those shown by the octahedral $\mathrm{Fe}^{2.5+}$ sextet of magnetite $[40,41]$. The contribution of this sextet increases significantly by decreasing the irradiation wavelength with values of $8 \%(532 \mathrm{~nm})$ and $25 \%(213 \mathrm{~nm})$. The spectrum of the sample deposited at $213 \mathrm{~nm}$ also contains an intense (20\%) paramagnetic doublet with hyperfine parameters $\delta=0.34 \mathrm{mms}^{-1}$ and $\Delta=1.00 \mathrm{mms}^{-1}$ characteristic of high spin $\mathrm{Fe}^{3+}$ 
in distorted octahedral coordination that might be related with the presence of small cobalt ferrite particles.

The spectra recorded from the films deposited at $300 \mathrm{~K}$ (Figs. 7 d-f) show, in all cases, the two sextets corresponding to $\mathrm{CoFe}_{2} \mathrm{O}_{4}$ plus the third broad component that we associate with the presence of magnetite. Additionally, the spectra of the samples obtained at $532 \mathrm{~nm}$ and $213 \mathrm{~nm}$ have paramagnetic contributions which are more intense than in the spectra of their counterparts deposited at $770 \mathrm{~K}$ with values of $10 \%$ and $34 \% v s .2 \%$ and $20 \%$, respectively. While the paramagnetic doublet of the sample deposited at $532 \mathrm{~nm}$ is also characteristic of high spin $\mathrm{Fe}^{3+}$ in distorted octahedral coordination and, therefore, compatible with the presence of small size cobalt ferrite particles, the chemical nature of the paramagnetic components observed in the spectrum of the sample deposited at $213 \mathrm{~nm}$ appears to be different. They consist in a singlet, $\delta=$ $0.02 \mathrm{mms}^{-1}$, that can be associated to superparamagnetic magnetite [46] and a doublet $\delta=1.00 \mathrm{mms}^{-1}, \Delta=0.85 \mathrm{mms}^{-1}$ most probably arising from the presence of $\mathrm{FeO}_{1-\mathrm{x}}$ [47]. Generally speaking, at any given laser wavelength, the spectra of the deposits produced at $300 \mathrm{~K}$ are much broader than those obtained at a $770 \mathrm{~K}$ what is indicative of phases having a poorer crystalline character and/or smaller particle size.

The spectra recorded from the samples deposited on STO substrates (Figs. 8 a-f) follow a similar trend to those obtained on $\mathrm{Si}$ substrates. The spectrum of the film deposited at $770 \mathrm{~K}$ at $1064 \mathrm{~nm}$ corresponds to a pure, genuine $\mathrm{CoFe}_{2} \mathrm{O}_{4}$ material. However, as the irradiation laser wavelength decreases the linewidth broadens and magnetite and $\mathrm{Fe}^{3+}$ paramagnetic contributions appear. In the case of the films deposited with the substrate at room temperature, the lines are always significantly broader than their counterparts deposited at $770 \mathrm{~K}$, the paramagnetic components, when present, are more intense and magnetite is observed even in the spectrum deposited at $1064 \mathrm{~nm}$. The 
spectrum recorded from the film deposited at $300 \mathrm{~K}$ and $213 \mathrm{~nm}$ contains only paramagnetic components: a singlet probably due to superparamagnetic magnetite and a doublet characteristic of high spin $\mathrm{Fe}^{3+}$ in distorted octahedral coordination. In these samples wustite $\left(\mathrm{FeO}_{1-\mathrm{x}}\right)$ is only observed, and in very small amounts $(5 \%)$, in the spectrum of the film produced at $532 \mathrm{~nm}$ and $300 \mathrm{~K}$.

Therefore, a high temperature of the substrate $(770 \mathrm{~K})$ and a laser wavelength in the infrared $(1064 \mathrm{~nm})$ give place to a pure, well-crystallized $\mathrm{CoFe}_{2} \mathrm{O}_{4}$ phase both on $\mathrm{Si}$ and STO substrates. The phase purity and the crystalline character/particle size of the film decrease with the laser wavelength and the substrate temperature. A lower substrate temperature $(300 \mathrm{~K})$ and a shorter wavelength $(213 \mathrm{~nm})$ lead to a marked superparamagnetic behaviour of the deposits. These results are in good agreement with the XRD, Raman, AFM and magnetic measurements presented above. The presence of magnetite in most of the spectra suggests that the parameters used during deposition lead, in general, to reducing conditions that preclude, except in one case, the formation of pure cobalt ferrite.

An interesting point is that the signal-to-noise ratio of the ICEMS data decreases with the laser wavelength used during the deposition. So, the percentage of effect in the spectra of the samples produced using infrared light is much larger than in the spectra of the samples deposited using ultraviolet light. This is undoubtedly related with the thickness of the films that AFM has shown to be in some cases as thin as $5 \mathrm{~nm}$ (see Table 2). Even with a so small film thickness we have managed to obtain a Mössbauer spectrum and we have been able to get some clues on the composition of the films where XRD and Raman spectroscopy have failed to do it as the data obtained from these techniques only showed the signal originated from the substrate. 
The Co 2p XPS spectra recorded from the different films showed in all cases an intense spin-orbit doublet with respective binding energies of the Co $2 \mathrm{p}_{3 / 2}$ and Co $2 \mathrm{p}_{1 / 2}$ core levels of $779.9 \mathrm{eV}$ and $795.9 \mathrm{eV}$ (Fig. 9). These binding energy values and the presence of intense shake-up satellite structure at 785.9 and $802.2 \mathrm{eV}$ are all indicative of the presence of $\mathrm{Co}^{2+}[48]$ as it should be expected from the presence of $\mathrm{CoFe}_{2} \mathrm{O}_{4}$ phases.

\subsection{Magnetic characterization}

Figure 10 presents the magnetization $v s$ applied field curves of the films grown on Si. The hysteresis loops of the films deposited at 770 and $300 \mathrm{~K}$ by irradiation at $1064 \mathrm{~nm}$ are consistent with pure cobalt ferrite composition, as a single magnetization reversal event is observed. For films obtained at 532 and $213 \mathrm{~nm}$ at the two substrate temperatures studied, the magnetization curves show a two-step reversal, in agreement with the coexistence of magnetically hard cobalt ferrite and magnetically soft magnetite confirmed by Mössbauer spectroscopy. In fact, it can be concluded from the two-step magnetization curves that cobalt ferrite and magnetite are exchange-decoupled. Interestingly, the film grown at $300 \mathrm{~K}$ upon irradiation at $532 \mathrm{~nm}$ presents the largest coercivity of all samples studied, with a value of 5710 Oe (Table 3). This is a large value even for pure cobalt ferrite [49], thus it is remarkably high for a hard-soft composite sample. Given that coercivity is a magnetic property dependent on extrinsic material properties such as the microstructure, it can be inferred from the data that the sample grown at $300 \mathrm{~K}$ and $532 \mathrm{~nm}$ presents the more appropriate microstructure to prevent demagnetization in terms of crystallinity, crystallite and grain size and concentration of defects. In particular, the structural characterization of the sample revealed that it contains the smallest cobalt ferrite particles of all samples studied 
(Table 1). We speculate that most of the ferrite particles of this sample are in a singledomain magnetic state due to their small size, which is at the origin of the exceptionally large coercivity. Even if its composition includes soft magnetite, the uncoupling of hard and soft phases is known to lead to larger coercivity values in these types of composites [50]. Figure 12 shows the magnetization curves obtained at 10 and $300 \mathrm{~K}$ of the CFO films grown at room temperature upon laser irradiation at $532 \mathrm{~nm}$ on $\mathrm{Si}$, where the largest difference in reversal fields between the two phases reveals the two-step reversal, i.e. the exchange-decoupling, more clearly. In general, coercivity decreases with temperature in all cases (Table 3), as a consequence of the increase in grain size with temperature in these polycrystalline films [50].

For the films grown on STO (Figure 11), a similar behavior is observed in the sense that the samples grown at $1064 \mathrm{~nm}$ present a single reversal event, whereas at shorter wavelengths (532 and $213 \mathrm{~nm}$ ) two exchange-decoupled magnetic phases can be detected, again in agreement with a coexistence of cobalt ferrite and magnetite. The extremely low coercive field measured for the films deposited at $300 \mathrm{~K}$ upon laser irradiation at $213 \mathrm{~nm}$ (Table 3) is consistent with a predominantly superparamagnetic film as inferred from Mössbauer spectroscopy. However, in this case, coercivity slightly increases with temperature in contrast with the decrease observed for Si. The fact that films grown on $\mathrm{STO} / \mathrm{Si}$ are single-crystalline/polycrystalline respectively can be in the origin of this opposite behavior. The slight increase for STO is likely the consequence of an improvement of crystallinity with temperature [51].

The saturation of magnetization for all the deposited CFO films was found to increase with substrate temperature and laser irradiation wavelengths. 


\section{Discussion}

The results gathered in this study show the dependence of the composition, crystallinity, structure and magnetic properties of the thin films grown by PLD from $\mathrm{CoFe}_{2} \mathrm{O}_{4}$ targets on the laser wavelength and on the type and temperature of the substrate. We have found that deposits produced by laser irradiation at $1064 \mathrm{~nm}$ at a substrate temperature of $770 \mathrm{~K}$ correspond to well-crystallized, genuine $\mathrm{CoFe}_{2} \mathrm{O}_{4}$. Under these conditions the films are polycrystalline on Si and single-crystal on STO, similarly to what was found in a previous study by some of us concerning PLD of magnetite films [42,52]. Heating the substrate at high temperatures during deposition has a beneficial effect on the composition and crystalline character of the films. Undoubtedly, these are found to be best choice of deposition parameters in order to obtain good quality CFO films.

In variation with the outcome at $1064 \mathrm{~nm}$, the nature of the films becomes more complex at shorter deposition wavelengths and lower substrate temperature. The films produced under these conditions are multiphasic and display a lower degree of crystallinity, giving place in some extreme cases, as the Mössbauer and magnetic measurements demonstrate, to completely superparamagnetic phases. Finally, all techniques used demonstrate that at shorter irradiation wavelengths the deposited films are extremely thin, with thickness around $5 \mathrm{~nm}$ in some cases.

AFM indicates that, while a shorter ablation wavelength produces a roughly more uniform film, the shape of the grains in such film is less defined, showing less developed facets than for longer wavelengths. Deposition at a lower substrate temperature also reduces the particle size, but again at the expense of less defined facets. XRD and AFM results correlate well as the most crystalline films are the ones grown at elevated temperature and under longer irradiation wavelengths. XRD results 
also show that the films are made of cobalt ferrite (although magnetite could not be ruled out due to the overlapping of the reflection peaks of the two compounds). The micro-Raman spectra prove the presence of cobalt ferrite, and are conclusive on the absence of any relevant features that would reflect a significant contribution of either magnetite or wustite. The intensity ratio of the 616 and $470 \mathrm{~cm}^{-1}$ bands drops with increasing substrate temperature suggesting that the inversion degree in the CFO spinelrelated structure might be dependent on the deposition temperature, with a higher substrate temperature promoting a larger inversion degree.

Except in the case of films grown at $1064 \mathrm{~nm}$ and $770 \mathrm{~K}$, Mössbauer spectra indicate the presence in the deposits of $\mathrm{Fe}^{2+}$ - containing phases, either magnetite or both wustite and magnetite. At some extent, the use of shorter wavelengths or room temperature during deposition results in the loss of oxygen and in the formation of reduced phases. Magnetic measurements are indicative, as in the case of Mössbauer results, of the presence of magnetically hard (cobalt ferrite) and soft (magnetite) phases for the films obtained upon irradiation at shorter wavelengths. This fact was revealed by the presence of two steps in the magnetization curves.

The presence of different phases (cobalt ferrite, magnetite, wustite) in the films fabricated upon laser irradiation at 532 and $213 \mathrm{~nm}$ can have its origin in the high atomization nature of the ablation plume at these laser wavelengths, giving rise to a high probability of oxygen loss. It is known that oxygen from the target is often lost in PLD growth of oxides [53-55]. In particular, the same conditions and experimental system have been used for the growth of magnetite from hematite [52] and for the growth of the present films. Thus for a hematite target, $\mathrm{Fe}^{3+}$ is partially reduced to $\mathrm{Fe}^{2+}$, resulting in high quality magnetite films. In the current case of a cobalt ferrite target, it is also suggested that $\mathrm{Fe}^{3+}$ is partially reduced to $\mathrm{Fe}^{2+}$ but the presence of $\mathrm{Co}^{2+}$ ions means that 
$\mathrm{Fe}^{2+}$ cannot be easily incorporated into the cobalt ferrite and instead segregates into a separate magnetite component. Once the cobalt ferrite is cobalt-rich, the known miscibility gap further favours the biphasic formation [56].

The differences observed in the quality and thickness of the CFO deposited films, upon various deposition conditions, can be related to the laser-target interaction, the subsequent plume expansion and the nucleation processes that take place on the substrate. For ns laser ablation, the formation of nanostructures with small nanoparticles and narrower size distribution at shorter wavelengths as observed herein has also been reported previously for other solid target materials [36,42]. Considering the linear absorption coefficients of the CFO target, $\alpha_{213} \approx 6.5 \times 10^{5} \mathrm{~cm}^{-1}, \alpha_{532} \approx 1 \times 10^{5} \mathrm{~cm}^{-1}$ and $\alpha_{1064} \approx 0.8 \times 10^{4} \mathrm{~cm}^{-1}[7]$, the heated subsurface layer thickness is only $15 \mathrm{~nm}$ at 213 $\mathrm{nm}$, while it amounts to around $100 \mathrm{~nm}$ for $532 \mathrm{~nm}$ and $1.25 \mu \mathrm{m}$ for $1064 \mathrm{~nm}$. Therefore, the experimentally observed tendency to produce smaller nanoparticles and thinner films by irradiation at $213 \mathrm{~nm}$ is related to the more atomized ablation plume and smaller size of the ejected atomic clusters produced in a reduced volume during the relaxation of the ablated target. The role of the temperature is concerned the mobility and coalescence of the deposited material on the surface, which is favored by increasing the substrate temperature. This indicates that thermal annealing of the small amount of material deposited at each laser pulse (a thousandth of a monolayer) is a crucial processing parameter to promote smooth growth, and thus, well defined cobalt ferrite crystallites. Finally, the choice of an appropriate substrate, such as STO, leads to the growth of an epitaxial single crystalline CFO.

\section{Conclusions}


Cobalt ferrite nanostructured deposits on $\mathrm{SrTiO}_{3}$ (100) and $\mathrm{Si}$ (100) substrates were obtained by PLD upon irradiation with a nanosecond Q-switched Nd:YAG laser at 213, 532, and $1064 \mathrm{~nm}$ and substrate temperatures of 300 and $770 \mathrm{~K}$. Morphological, microstructural and compositional characterization of the films was carried out by means of AFM, SEM/EDX, XRD, micro-Raman, XPS and Mössbauer spectroscopy, while the SQUID technique was used for magnetic characterization. The obtained deposits are mostly stoichiometric cobalt ferrite. The observed trend of improved stoichiometry and crystallinity of the deposits as the laser wavelength and substrate temperature increase provides the possibility of tailoring the properties of magnetic nanostructured films grown by PLD. The best quality deposits, having the right cobalt ferrite stoichiometry, as indicated by Mössbauer spectroscopy and SQUID measurements, were grown by ablation at $1064 \mathrm{~nm}$ and at a substrate temperature of $770 \mathrm{~K}$. Thin films fabricated under these conditions on $\mathrm{Si}$ (100) present a polycrystalline cobalt ferrite nanoparticles of geometrical shape with a well-defined edges, in a mixture of cubic and orthogonal prisms, with sizes in the range of 50-150 nm. The nanostructured cobalt ferrite films deposited on STO (100) under the mentioned conditions show an epitaxial monocrystalline nature.

The nanostructures fabricated at 532 and $213 \mathrm{~nm}$ both at room temperature and at $770 \mathrm{~K}$ on Si and STO display mono- and polycrystalline nature respectively, with a biphasic composition mainly consisting on cobalt ferrite and magnetite without ruling out the presence of wustite.

The use of the infrared wavelength of $1064 \mathrm{~nm}$, poorly absorbed by the target in PLD experiments at higher substrate temperatures which governs the aggregation of ejected plume species on the heated surface, together with self-prepared cobalt ferrite 
sintered targets, enhances the quality of CFO thin films and allows preparing low-cost pure and genuine CFO nanostructured thin films for different applications.

\section{Acknowledgments}

This research was supported by the Spanish Ministry of Economy and Competitiveness (MINECO) through Projects CTQ2016-75880-P, CTQ2013-43086-P and MAT201564110-C2-1-P. M. O. and E. R. thank CSIC and RYC-2011-08069 (Ramón y Cajal Programme) for contracts. We thank CSIC Intramural Project PIE 201560E068 and financial support from the European Commission through the project NANOPYME FP7-NMP-2012-SMALL-6 NANOPYME (n 310516) and AMPHIBIAN H2020NMBP-2016-720853. We are grateful to Prof. T. Ezquerra (IEM, CSIC) for the use of the AFM system. M. Juanco (ICA, CSIC), D. Gómez (ICTP, CSIC) and M. V. Cañamares (IEM, CSIC) are acknowledged for XRD, SEM/EDS and micro-Raman measurements, respectively. 


\section{References}

[1] R. Ji, C. Cao, Z. Chen, H. Zhai, Ju. Bai, Solvothermal synthesis of $\mathrm{Co}_{\mathbf{x}} \mathrm{Fe}_{3-\mathrm{x}} \mathrm{O}_{4}$ spheres and their microwave absorption properties, J. Mater. Chem. C 2 (2014) 5944-5953.

[2] V. Thakare, G. Xing, H. Peng, A. Rana, O. Game, P.A. Kumar, A. Banpukar, Y. Kolekar, K. Ghosh, T. Wu, D.D. Sarma, S.B. Ogale, High sensitivity low field magnetically gated resistive switching in $\mathrm{CoFe}_{2} \mathrm{O}_{4} / \mathrm{La}_{0.66} \mathrm{Sr}_{0.34} \mathrm{MnO}_{3}$ heterostructure, Appl. Phys. Lett. 100 (2012) 172412.

[3] Y.K. Takahashi, S. Kasai, T. Furubayashi, S. Mitani, K. Inomata, K. Hono, High spin-filter efficiency in a Co ferrite fabricated by a thermal oxidation, Appl. Phys. Lett. 96 (2010) 072512. [4] A.V. Ramos, T.S. Santos, G.X. Miao, M.J. Guittet, J.B. Moussy, J.S. Moodera, Influence of oxidation on the spin-filtering properties of $\mathrm{CoFe}_{2} \mathrm{O}_{4}$ and the resultant spin polarization, Phys. Rev. B. 78 (2008) 180402(R).

[5] A. Chaudhuri, K. Mandal, Large magnetoelectric properties in $\mathrm{CoFe}_{2} \mathrm{O}_{4}: \mathrm{BaTiO}_{3}$ core-shell nanocomposites, J. Magn. Magn. Mater. 377 (2015) 441-445.

[6] E.L. Verde, G.T. Landi, J.A. Gomes, M.H. Sousa, A.F. Bakuzis, Magnetic hyperthermia investigation of cobalt ferrite nanoparticles: Comparison between experiment, linear response theory, and dynamic hysteresis simulations, J. Appl. Phys. 111 (2012) 123902.

[7] B. S. Holinsworth, D. Mazumdar, H. Sims, Q.-C. Sun, M. K. Yurtisigi, S. K. Sarker, A. Gupta, W. H. Butler, and J. L. Musfeldt, Chemical tuning of the optical band gap in spinel ferrites: $\mathrm{CoFe}_{2} \mathrm{O}_{4}$ vs $\mathrm{NiFe}_{2} \mathrm{O}_{4}$, Appl. Phys. Lett. 103 (2013) 082406.

[8] A. Franco Jr., F.C. e Silva, High temperature magnetic properties of cobalt ferrite nanoparticles, Appl. Phys. Lett. 96 (2010) 172505.

[9] A. Muhammad, R.S. Turtelli, M. Kriegisch, R. Grossinger, F. Kubel, T. Konegger, Large enhancement of magnetostriction due to compaction hydrostatic pressure and magnetic annealing in $\mathrm{CoFe}_{2} \mathrm{O}_{4}$, J. Appl. Phys. 111 (2012) 013918.

[10] K. Khaja Mohaideen, P.A. Joy, High magnetostriction parameters for low-temperature sintered cobalt ferrite obtained by two-stage sintering, J. Magn. Magn. Mater. 371 (2014) 121. 
[11] I. Sharifi, H. Shokrollahi, M.M. Doroodm, R. Safi, Magnetic and structural studies on $\mathrm{CoFe}_{2} \mathrm{O}_{4}$ nanoparticles synthesized by co-precipitation, normal micelles and reverse micelles methods, J. Magn. Magn. Mater. 324 (2012) 1854-1861.

[12] C.N. Chinnasamy, B. Jeyadevan, K. Shinoda, K. Tohji, D.J. Djayaprawira, Unusually high coercivity and critical single-domain size of nearly monodispersed $\mathrm{CoFe}_{2} \mathrm{O}_{4}$ nanoparticles, Appl. Phys. Lett. 83 (2003) 2862.

[13] P. Kuruva, S. Matteppanavar, S. Srinath, T. Thomas, Size Control and Magnetic Property Trends in Cobalt Ferrite Nanoparticles Synthesized Using an Aqueous Chemical Route, IEEE Trans. Magn. 50 (2014) 5200108.

[14] A.T. Ngo, P. Bonville, M.P. Pileni, Spin canting and size effects in nanoparticles of nonstoichiometric cobalt ferrite, J. Appl. Phys. 89 (2001) 3370.

[15] D.L. Leslie-Pelecky, R.D. Rieke, Magnetic Properties of Nanostructured Materials, Chem. Mater. 8 (1996) 1770-1783.

[16] S.A. Corr,Y.P. Rakovich, Y.K. Gun'ko, Multifunctional Magnetic-fluorescent Nanocomposites for Biomedical Applications, Nanoscale Res. Lett. 3 (2008) 87-104.

[17] D. Mukherjee, T. Dhakal, M. H. Phan, H. Srikanth, P. Mukherjee, S. Witanachchi, Role of crystal orientation on the magnetic properties of $\mathrm{CoFe}_{2} \mathrm{O}_{4}$ thin films grown on $\mathrm{Si}(100)$ and $\mathrm{Al}_{2} \mathrm{O}_{3}$ (0001) substrates using pulsed laser deposition, Physica. B. Condens. Matter. 406 (2011) 2663-2668.

[18] T. Dhakal, D. Mukherjee, R. Hyde, P. Mukherjee, M. H. Phan, H. Srikanth, S. Witanachchi, Magnetic anisotropy and field switching in cobalt ferrite thin films deposited by pulsed laser ablation, J. Appl. Phys. 107 (2010) 053914.

[19] W. Huang, J. Zhu, H. Z. Zeng, X. H. Wei, Y. Zhang, Y. R. Li, Strain induced magnetic anisotropy in highly epitaxial $\mathrm{CoFe}_{2} \mathrm{O}_{4}$ thin films, Appl. Phys. Lett. 89 (2006) 262506.

[20] M. C. Terzzoli, S. Duhalde, S. Jacobo, L. Steren, C. Moina, High perpendicular coercive field of $\mathrm{CoFe}_{2} \mathrm{O}_{4}$ thin films deposited by PLD, J. Alloys Compd. 369 (2004) 209-212.

[21] N. Hiratsuka, M. Nozawa, K. Kakizaki, Preparation and properties of $\left(\mathrm{CoFe}_{2} \mathrm{O}_{4}\right)-(\mathrm{Co}-\mathrm{CoO})$ composite films for perpendicular magnetic recording, J. Magn. Soc. Jpn. 20 (1996) 53-56. 
[22] S. N. Okuno, S. Hashimoto, K. Inomata, Preferred Crystal Orientation of Cobalt Ferrite Thin-Films Induced by Ion-Bombardment during Deposition, J. Appl. Phys. 71 (1992) 59265929.

[23] N. C. Pramanik, T. Fujii, M. Nakanishi, J. Takada, Development of $\mathrm{Co}_{1+x} \mathrm{Fe}_{2-x} \mathrm{O}_{4}(\mathrm{x}=0$ 0.5) thin films on $\mathrm{SiO}_{2}$ glass by the sol-gel method and the study of the effect of composition on their magnetic properties, Mater. Lett. 59 (2005) 88-93.

[24] J. G. Lee, J. Y. Park, Y. J. Oh, C. S. Kim, Magnetic properties of CoFe2O4 thin films prepared by a sol-gel method, J. Appl. Phys. 84 (1998) 2801-2804.

[25] A. Raghunathan, I. C. Nlebedim, D. C. Jiles, J. E. Snyder, Growth of crystalline cobalt ferrite thin films at lower temperatures using pulsed-laser deposition technique, J. Appl. Phys. 107 (2010) 09A516.

[26] C. Araújo, B. G. Almeida, M. Aguiar, J. A. Mendes, Structural and magnetic properties of $\mathrm{CoFe}_{2} \mathrm{O}_{4}$ thin films deposited by laser ablation on Si (001) substrates, Vacuum 82 (2008) 14371440.

[27] X. S. Gao, D. H. Bao, B. Birajdar, T. Habisreuther, R. Mattheis, M. A. Schubert, M. Alexe, D. Hesse, Switching of magnetic anisotropy in epitaxial $\mathrm{CoFe}_{2} \mathrm{O}_{4}$ thin films induced by $\mathrm{SrRuO}_{3}$ buffer layer, J. Phys. D: Appl. Phys. 42 (2009) 175006.

[28] M. Ning, J. Li, C. K. Ong, S. J. Wang, High perpendicular coercive field of (100)-oriented $\mathrm{CoFe}_{2} \mathrm{O}_{4}$ thin films on $\mathrm{Si}(100)$ with MgO buffer layer, J. Appl. Phys. 103 (2008) 013911.

[29] P. D. Thang, G. Rijnders, D. H. A. Blank, Stress-induced magnetic anisotropy of $\mathrm{CoFe}_{2} \mathrm{O}_{4}$ thin films using pulsed laser deposition, J. Magn. Magn. Mater. 310 (2007) 2621-2623.

[30] P. C. Dorsey, P. Lubitz, D. B. Chrisey, J. S. Horwitz, $\mathrm{CoFe}_{2} \mathrm{O}_{4}$ thin films grown on (100) MgO substrates using pulsed laser deposition, J. Appl. Phys. 79 (1996) 6338-6340.

[31] D.B. Chrisey, G.K. Hubler, Pulsed Laser Deposition of Thin Films, John Wiley \& Sons, New York, 1994.

[32] M.N. Ashfold, F. Claeyssens, G.M. Fuge, S.J. Henley, Pulsed laser ablation and deposition of thin films, Chem. Soc. Rev. 33 (2004) 23-31. 
[33] R. Eason, Pulsed Laser Deposition of Thin Films: Applications-Led Growth of Functional Materials, John Wiley \& Sons, New York, 2006.

[34] V. Craciun, D. Craciun, Evidence for volume boiling during laser ablation of single crystalline targets, Appl. Surf. Sci. 138-139 (1999) 218-223.

[35] G. Koren, A. Gupta, R.J. Baseman, M.I. Lutwyche, R.B. Laibowitz, Laser wavelength dependent properties of $\mathrm{YBa} 2 \mathrm{Cu} 3 \mathrm{O} 7$-thin films deposited by laser ablation, Appl. Phys. Lett. $\mathbf{5 5}$ (1989) 2450-2452.

[36] M. Sanz, M. Walczak, M. Oujja, A. Cuesta, M. Castillejo, Nanosecond pulsed laser deposition of $\mathrm{TiO}_{2}$ : nanostructure and morphology of deposits and plasma diagnosis, Thin Solid Films 517 (2009) 6546-6552.

[37] A. V. Ramos, M.-J. Guittet, J.-B. Moussy, R. Mattana, C. Deranlot, F. Petroff, C. Gatel, Room temperature spin filtering in epitaxial cobalt-ferrite tunnel barriers, Appl. Phys. Lett. 91(12) (2007) 122107.

[38] M. Coll, Josep M. Montero M., J. Gazquez, K. Nielsch, X. Obradors, and T. Puig. Low Temperature Stabilization of Nanoscale Epitaxial Spinel Ferrite Thin Films by Atomic Layer Deposition. Adv. Funct. Mater. 24(34) (2014) 5368-5374.

[39] A. Rafferty, T. Prescott, D. Brabazonet, Sintering behaviour of cobalt ferrite ceramic, Ceramics International 34 (2008) 15.

[40] J. de la Figuera, A. Quesada, L. Martín-García, M. Sanz, M. Oujja, M. Castillejo, A. Mascaraque, A.T. N'Diaye, M. Foerster, L. Aballe, J.F. Marco, Mössbauer and Magnetic Properties of Coherently Mixed Magnetite-Cobalt Ferrite Grown by Infrared Pulsed-Laser Deposition, Croatica Quimica Acta 88 (2015) 453.

[41] J. de la Figuera, A. Quesada, L. Martín-García, M. Sanz, M. Oujja, E. Rebollar, M. Castillejo, P. Prieto, A. Muñoz-Martin, L. Aballe, J.F. Marco, Self-organized single crystal mixed magnetite/cobalt ferrite films grown by infrared pulsed-laser deposition, Appl. Surf. Sci. 359 (2015) 480. 
[42] M. Sanz, M. Oujja, E. Rebollar, J. F. Marco, J. de la Figuera, M. Monti, A. Bollero, J. Camarero, F. J. Pedrosa, M. García-Hernández, M. Castillejo, Stoichiometric magnetite grown by infrared nanosecond pulsed laser deposition, Appl. Surf. Sci. 282 (2013) 642-651.

[43] J.R. Gancedo, M. Gracia, J.F. Marco, CEMS methodology, Hyperf. Interact. 66 (1991) 8393.

[44] P. Chandramohan, M.P. Srinivasan, S. Velmurugan, S.V. Narasimhan, Cation distribution and particle size effect on Raman spectrum of $\mathrm{CoFe}_{2} \mathrm{O}_{4}$, J. Solid State Chem. 184 (2011) 89-96. [45] X. Fan, J. Guan, X. Cao, W. Wang, F. Mou, Low-Temperature Synthesis, Magnetic and Microwave Electromagnetic Properties of Substoichiometric Spinel Cobalt Ferrite Octahedra, Eur. J. Inorg. Chem. 2010 (2010) 419-426.

[46] A.G. Roca, J. F. Marco, M. P. Morales, C.J. Serna, Effect of Nature and Particle Size on Properties of Uniform Magnetite and Maghemite Nanoparticles, J. Phys. Chem. C 111 (2007) $18577-18584$

[47] E. Murad, J.H. Johnson, "Iron oxides and oxyhydroxides" G.L. Long (Ed.), Mössbauer Spectroscopy Applied to Inorganic Chemistry, Plenum Press, New York (1984) Chapter 12 [48] J.F. Marco, J.R. Gancedo, J. Ortiz, J.L Gautier, Characterization of the spinel-related oxides $\mathrm{Ni}_{\mathrm{x}} \mathrm{Co}_{3-\mathrm{x}} \mathrm{O}_{4}(\mathrm{x}=0.3,1.3,1.8)$ prepared by spray pyrolysis at $350{ }^{\circ} \mathrm{C}$, Appl. Surf. Sci. 227 (2004) 175-186.

[49] F. J. Pedrosa, J. Rial, K. M. Golasinski, M. N. Guzik, A. Quesada, J. F. Fernández, S. Deledda, J. Camarero, A. Bollero, Towards high performance $\mathrm{CoFe}_{2} \mathrm{O}_{4}$ isotropic nanocrystalline powder for permanent magnet applications, Appl. Phys. Lett. 109 (2016) 223105.

[50] A. Quesada, C. Granados-Miralles, A. López-Ortega, S. Erokhin, E. Lottini, J. Pedrosa, A. Bollero, A.M. Aragón, F. Rubio-Marcos, M. Stingaciu, G. Bertoni, C. de Julián Fernández, C. Sangregorio, J.F. Fernández, D. Berkov, M. Christensen, Energy Product Enhancement in Imperfectly Exchange-Coupled Nanocomposite Magnets, Adv. Electron. Mater. (2016) 1500365. 
[51] A. Quesada, F. Rubio-Marcos, J. F. Marco, F. J. Mompean, M. García-Hernández, J. F. Fernández, On the origin of remanence enhancement in exchange-uncoupled $\mathrm{CoFe}_{2} \mathrm{O}_{4}$-based composites, Appl. Phys. Lett. 105 (2014) 202405.

[52] M. Monti, M. Sanz, M. Oujja, E. Rebollar, M. Castillejo, F. J. Pedrosa, A. Bollero, J. Camarero, J.-L. F. Cuñado, N. M. Nemes, F. J. Mompean, M. Garcia-Hernández, S. Nie, K. F. McCarty, A. T. N'Diaye, G. Chen, A. K. Schmid, J. F. Marco, J. de la Figuera. Room temperature in-plane $<100>$ magnetic easy axis for $\mathrm{Fe}_{3} \mathrm{O}_{4} / \mathrm{SrTiO}_{3}(001)$ : Nb grown by infrared pulsed laser deposition, J. Appl. Phys. 114 (2013) 223902.

[53] H. M. Christen and G. Eres, Recent advances in pulsed-laser deposition of complex oxides, J. Phys.: Condens. Matter, 20 (2008) 264005.

[54] H.N. Lee, S.S.A. Seo, W.S. Choi, C.M. Rouleau, Growth control of oxygen stoichiometry in homoepitaxial SrTiO3 films by pulsed laser epitaxy in high vacuum, Sci. Rep. 6 (2016) 19941.

[55] L. Martín-García, I. Bernal-Villamil, M. Oujja, E. Carrasco, R. Gargallo-Caballero, M. Castillejo, J.F. Marco, S. Gallego, J. de la Figuera, Unconventional properties of nanometric $\mathrm{FeO}(111)$ films on $\mathrm{Ru}(0001)$ : stoichiometry and surface structure, J. Mater. Chem. C. 4 (2016) $1850-1859$.

[56] M. Takahashi, M.E. Fine, Magnetic behavior of quenched and aged $\mathrm{CoFe}_{2} \mathrm{O}_{4} / \mathrm{Co}_{3} \mathrm{O}_{4}$ alloys, J. Appl. Phys. 43 (1972) 4205-4216. 
Table 1. Nanocrystalline domain sizes (nm) of $\mathrm{CoFe}_{2} \mathrm{O}_{4}$ nanostructures obtained by PLD upon different laser ablation and substrate conditions.

\begin{tabular}{ccccccc}
\hline & \multicolumn{2}{c}{$1064 \mathrm{~nm}$} & \multicolumn{2}{c}{$532 \mathrm{~nm}$} & \multicolumn{2}{c}{$213 \mathrm{~nm}$} \\
& $300 \mathrm{~K}$ & $770 \mathrm{~K}$ & $300 \mathrm{~K}$ & $770 \mathrm{~K}$ & $300 \mathrm{~K}$ & $770 \mathrm{~K}$ \\
\hline $\mathrm{Si}(100)$ & 26 & 76 & ---- & 65 & ---- & ---- \\
\hline STO (100) & 14 & 78 & 11 & 43 & ---- & 27 \\
\hline
\end{tabular}

Table 2. Thickness, roughness and $\mathrm{Fe} / \mathrm{Co}$ ratio of $\mathrm{CFO}$ deposits obtained upon irradiation at different wavelengths and substrate nature and temperature, as determined by AFM and $\mathrm{SEM} / \mathrm{EDX}$.

\begin{tabular}{|c|c|c|c|c|c|}
\hline $\begin{array}{c}\text { Laser } \\
\text { wavelength } \\
(\mathrm{nm})\end{array}$ & Substrate & $\begin{array}{c}\text { Temperature } \\
\text { (K) }\end{array}$ & $\begin{array}{l}\text { Thickness } \\
\text { (nm) }\end{array}$ & $\begin{array}{l}\text { Roughness } \\
\text { (nm) }\end{array}$ & $\mathrm{Fe} / \mathrm{Co}$ ratio* \\
\hline \multirow{4}{*}{1064} & \multirow{2}{*}{$\mathrm{Si}$} & 300 & $164 \pm 8$ & $2.4 \pm 0.8$ & 1.8 \\
\hline & & 770 & $275 \pm 43$ & $6.1 \pm 0.3$ & 1.7 \\
\hline & \multirow{2}{*}{ STO } & 300 & $274 \pm 49$ & $1.0 \pm 0.3$ & 1.8 \\
\hline & & 770 & $196 \pm 39$ & $0.9 \pm 0.4$ & 1.8 \\
\hline \multirow{4}{*}{532} & \multirow{2}{*}{$\mathrm{Si}$} & 300 & $54 \pm 6$ & $1.3 \pm 0.5$ & 1.9 \\
\hline & & 770 & $62 \pm 11$ & $3.4 \pm 0.2$ & 1.6 \\
\hline & \multirow{2}{*}{ STO } & 300 & $42 \pm 8$ & $1.3 \pm 0.4$ & 1.9 \\
\hline & & 770 & $55 \pm 9$ & $2.1 \pm 1.5$ & 1.9 \\
\hline \multirow{4}{*}{213} & \multirow{2}{*}{$\mathrm{Si}$} & 300 & $18 \pm 11$ & $1.8 \pm 0.9$ & 1.6 \\
\hline & & 770 & $36 \pm 7$ & $2.4 \pm 0.1$ & 1.8 \\
\hline & \multirow{2}{*}{ STO } & 300 & $8 \pm 2$ & $0.5 \pm 0.1$ & 1.5 \\
\hline & & 770 & $5 \pm 2$ & $1.4 \pm 0.4$ & 2.0 \\
\hline
\end{tabular}

* For the observed deviations from the stoichiometric ratio of 2, see Section 3.3. 
Table 3. Coercivity $\left(\mathrm{H}_{\mathrm{c}}\right)$ and saturation magnetization $\left(\mathrm{M}_{\mathrm{s}}\right)$ of the CFO films at $300 \mathrm{~K}$ grown by PLD by irradiation at 1064, 532 and $213 \mathrm{~nm}$ on STO and Si substrates at 770 and $300 \mathrm{~K}$.

\begin{tabular}{|c|c|c|c|c|}
\hline $\begin{array}{c}\text { Laser } \\
\text { wavelength } \\
(\mathrm{nm})\end{array}$ & Substrate & Temperature (K) & $\mathrm{H}_{\mathrm{c}}(\mathrm{Oe})$ & $\mathrm{M}_{\mathrm{s}}\left(10^{-3} \mathrm{emu}\right)$ \\
\hline \multirow{4}{*}{1064} & \multirow{2}{*}{$\mathrm{Si}$} & 300 & 4910 & 2.15 \\
\hline & & 770 & 2250 & 4.2 \\
\hline & \multirow{2}{*}{ STO } & 300 & 4420 & 1.25 \\
\hline & & 770 & 4640 & 1.52 \\
\hline \multirow{4}{*}{532} & \multirow{2}{*}{$\mathrm{Si}$} & 300 & 5710 & 0.18 \\
\hline & & 770 & 1400 & 0.36 \\
\hline & \multirow{2}{*}{ STO } & 300 & 4310 & 0.2 \\
\hline & & 770 & 4830 & 0.38 \\
\hline \multirow{4}{*}{213} & \multirow{2}{*}{$\mathrm{Si}$} & 300 & 2260 & 0.051 \\
\hline & & 770 & 1120 & 0.053 \\
\hline & \multirow{2}{*}{ STO } & 300 & 80 & 0.02 \\
\hline & & 770 & 670 & 0.07 \\
\hline
\end{tabular}




\section{Figure captions}

Figure 1. XRD patterns recorded from PLD films grown at 1064 (a, d), 532 (b, e) and $213 \mathrm{~nm}$ (c, f) on a $\mathrm{Si}(100)$ substrate at $770 \mathrm{~K}$ (left column) and $300 \mathrm{~K}$ (right column).

Figure 2. XRD patterns of PLD films grown at 1064 (a, d), 532 (b, e) and $213 \mathrm{~nm}$ (c, f) on a STO (100) substrate at $770 \mathrm{~K}$ (left column) and $300 \mathrm{~K}$ (right column).

Figure 3. Micro-Raman spectra of PLD films grown at $1064 \mathrm{~nm}$ (a, c) and $532 \mathrm{~nm}$ (b, d) on a Si (100) substrate at $770 \mathrm{~K}$ (left column) and $300 \mathrm{~K}$ (right column).

Figure 4. Micro-Raman spectra of PLD nanostructured films grown at 1064 (a, b) on a STO (100) substrate at $770 \mathrm{~K}$ (left column) and $300 \mathrm{~K}$ (right column).

Figure 5. Height AFM images of the CFO deposits obtained on $\mathrm{Si}$ (100) substrate at 770 and $300 \mathrm{~K}$, upon laser irradiation at: (a, d) $1064 \mathrm{~nm}$, (b, e) $532 \mathrm{~nm}$ and (c, f) $213 \mathrm{~nm}$. All the images are $40 \mathrm{~nm}$ high and the scale bar is $400 \mathrm{~nm}$.

Figure 6. Height AFM images of the CFO deposits obtained on STO (100) substrate at 770 and $300 \mathrm{~K}$, upon laser irradiation at: (a, d) $1064 \mathrm{~nm}$, (b, e) $532 \mathrm{~nm}$ and (c, f) $213 \mathrm{~nm}$. All the images are $40 \mathrm{~nm}$ high and the scale bar is $400 \mathrm{~nm}$.

Figure 7. ICEMS spectra of the deposits formed on $\mathrm{Si}$ (100) substrates at temperatures of 770 and $300 \mathrm{~K}$, upon laser irradiation at: (a, d) $1064 \mathrm{~nm}$, (b, e) $532 \mathrm{~nm}$ and (c, f) $213 \mathrm{~nm}$.

Figure 8. ICEMS spectra of the deposits formed on STO (100) substrates at temperatures of 770 and $300 \mathrm{~K}$, upon laser irradiation at: (a, d) $1064 \mathrm{~nm}$, (b, e) $532 \mathrm{~nm}$ and (c, f) $213 \mathrm{~nm}$.

Figure 9. Co 2p XPS spectrum recorded from the film deposited on $\mathrm{Si}(100)$ at $770 \mathrm{~K}$ at 1064 nm.

Figure 10. Magnetization as a function of applied magnetic field of cobalt ferrite films on $\mathrm{Si}$ (100) at 770 and $300 \mathrm{~K}$, upon laser irradiation at: (a, d) $1064 \mathrm{~nm}$, (b, e) $532 \mathrm{~nm}$ and (c, f) 213 nm.

Figure 11. Magnetization as a function of applied magnetic field of cobalt ferrite films on STO (100) at 770 and $300 \mathrm{~K}$, upon laser irradiation at: (a, d) $1064 \mathrm{~nm}$, (b, e) $532 \mathrm{~nm}$ and $(\mathrm{c}, \mathrm{f}) 213 \mathrm{~nm}$.

Figure 12. Magnetization as a function of applied magnetic field of cobalt ferrite deposits on $\mathrm{Si}$ (100) at 10 and $300 \mathrm{~K}$ upon laser irradiation at $532 \mathrm{~nm}$ and substrate temperature of $300 \mathrm{~K}$. 
Figure 1

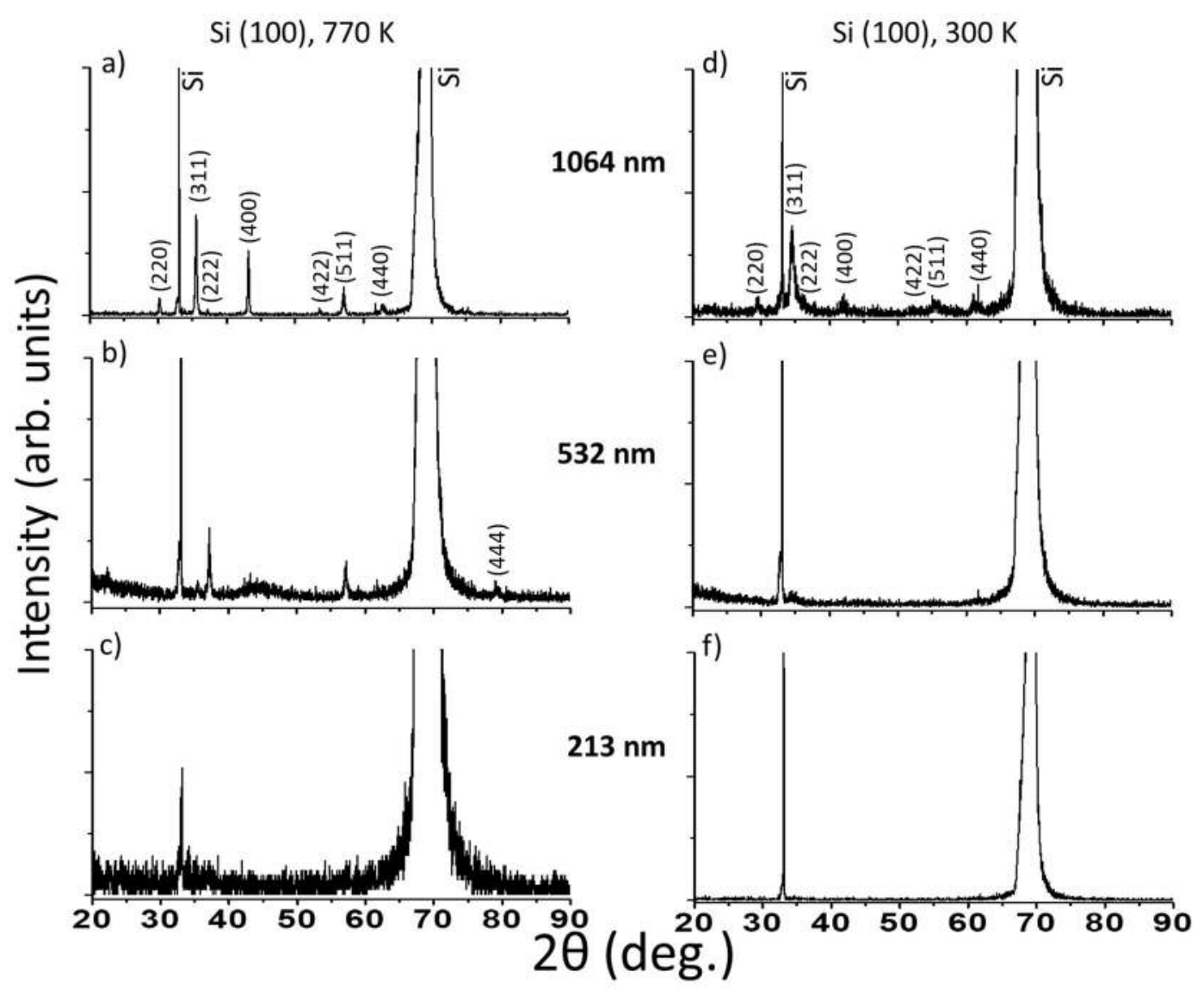


Figure 2

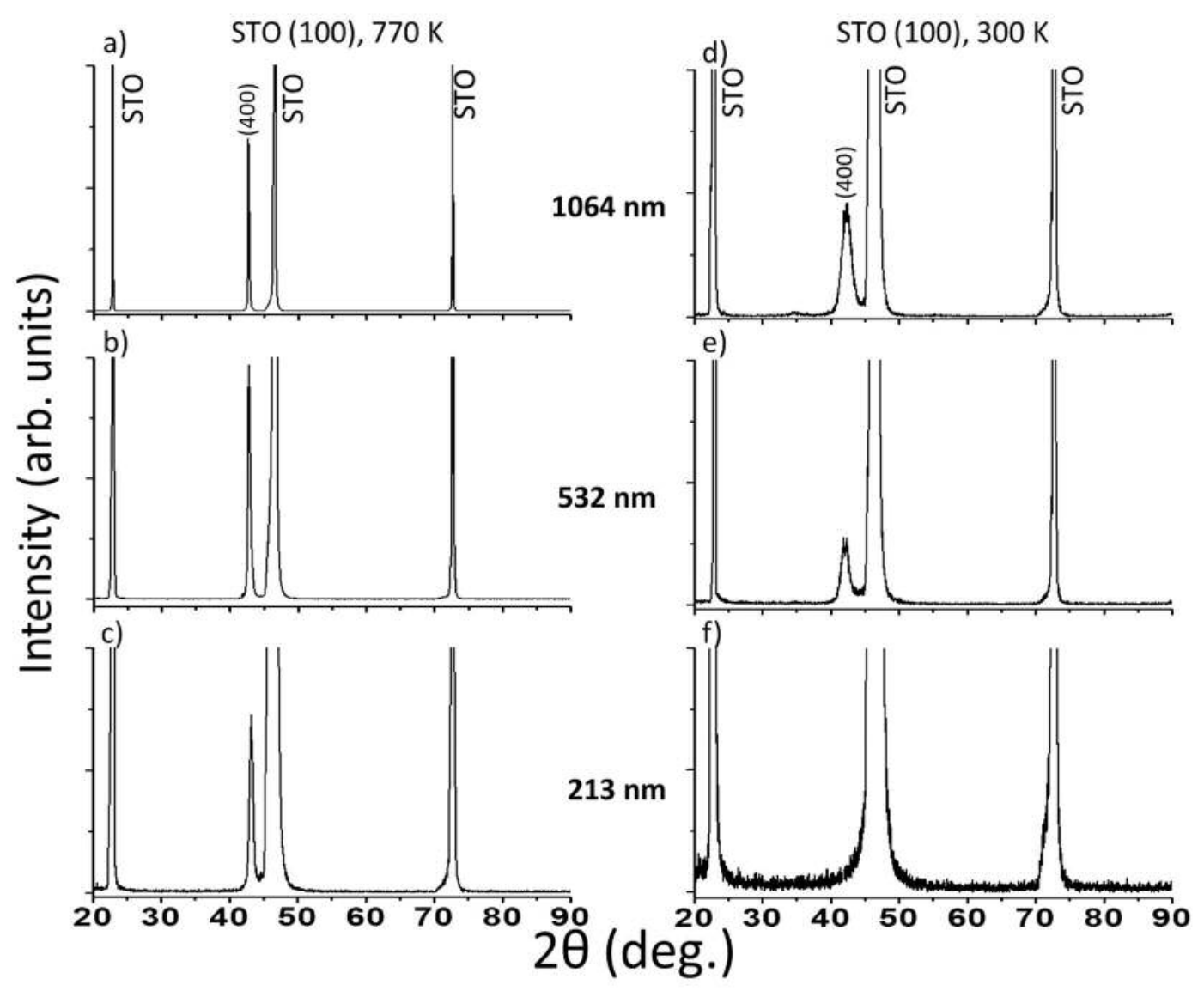


Figure 3

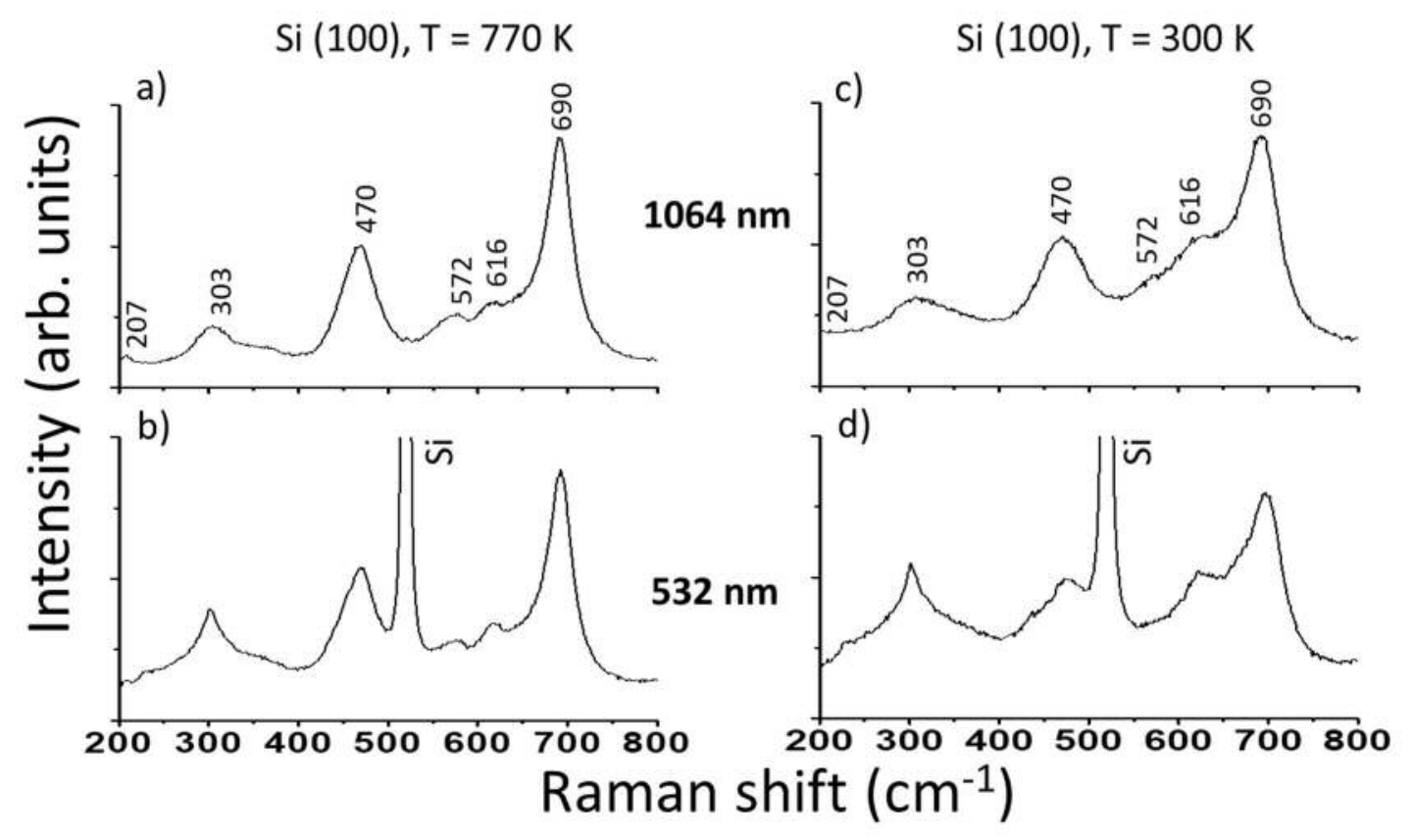


Figure 4

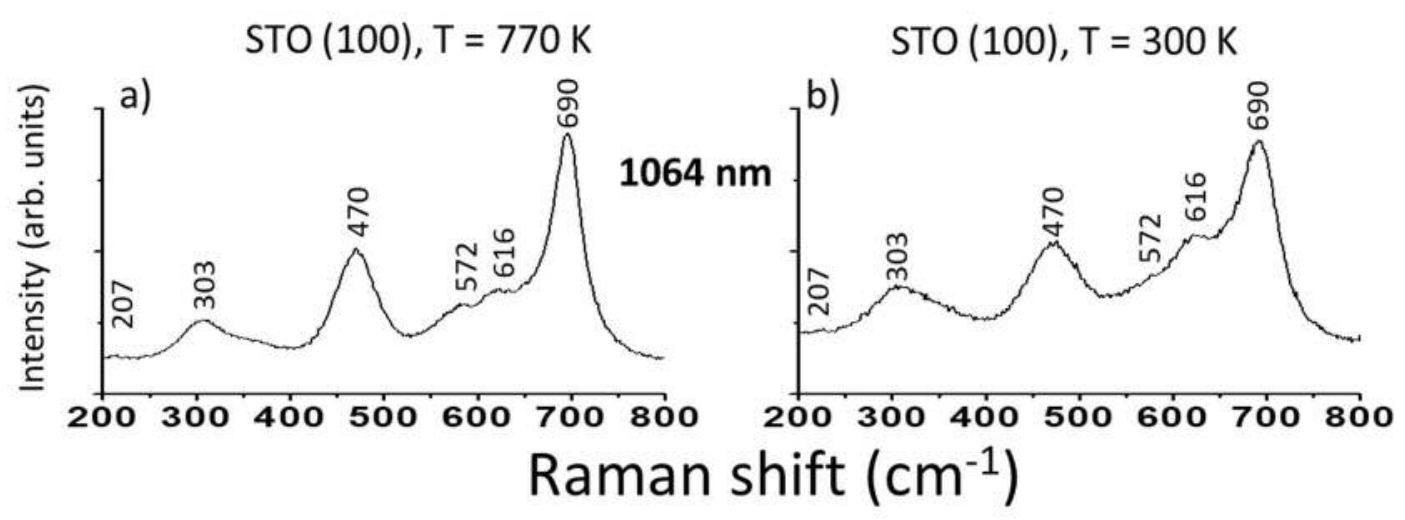


Figure 5
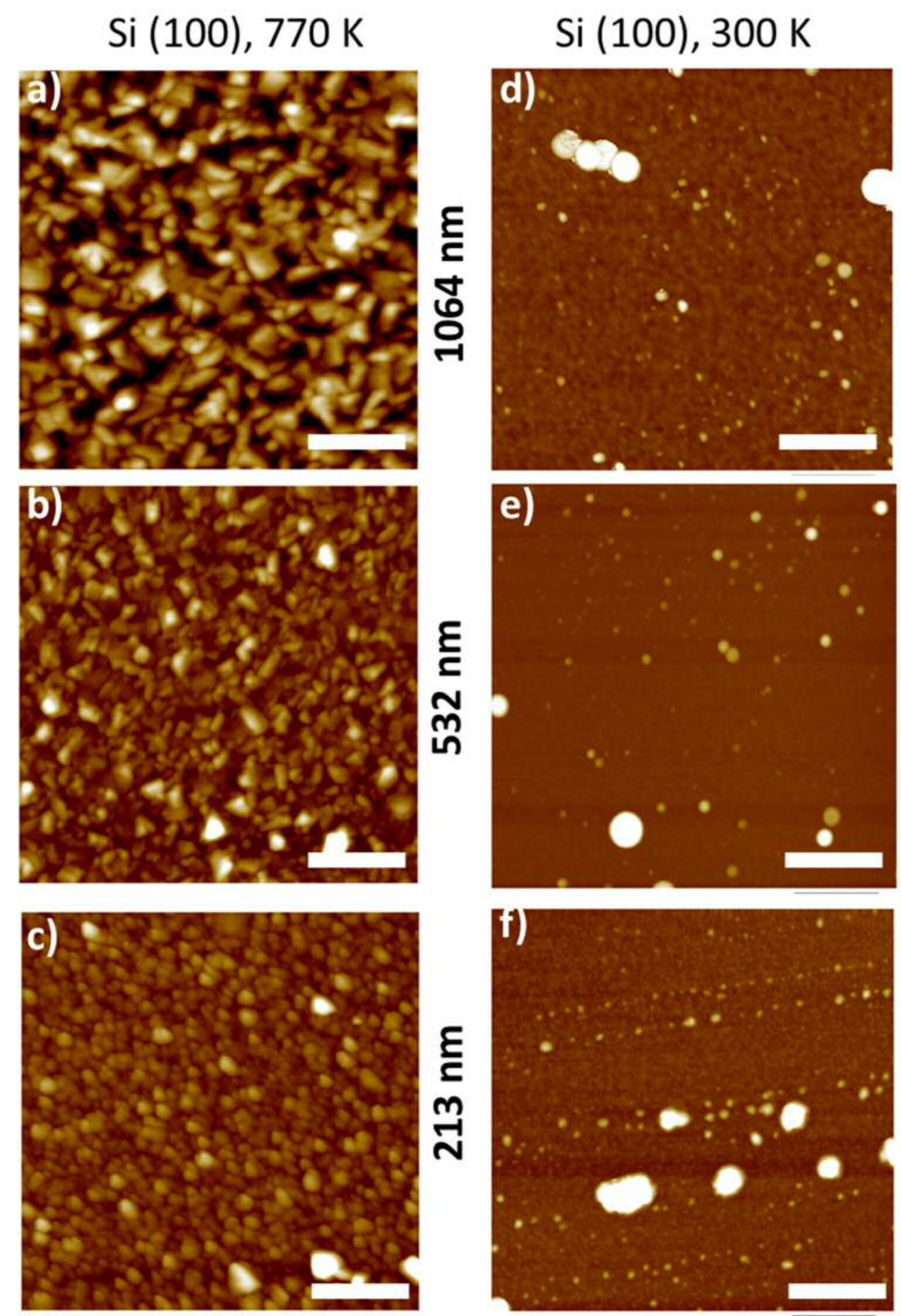
Figure 6
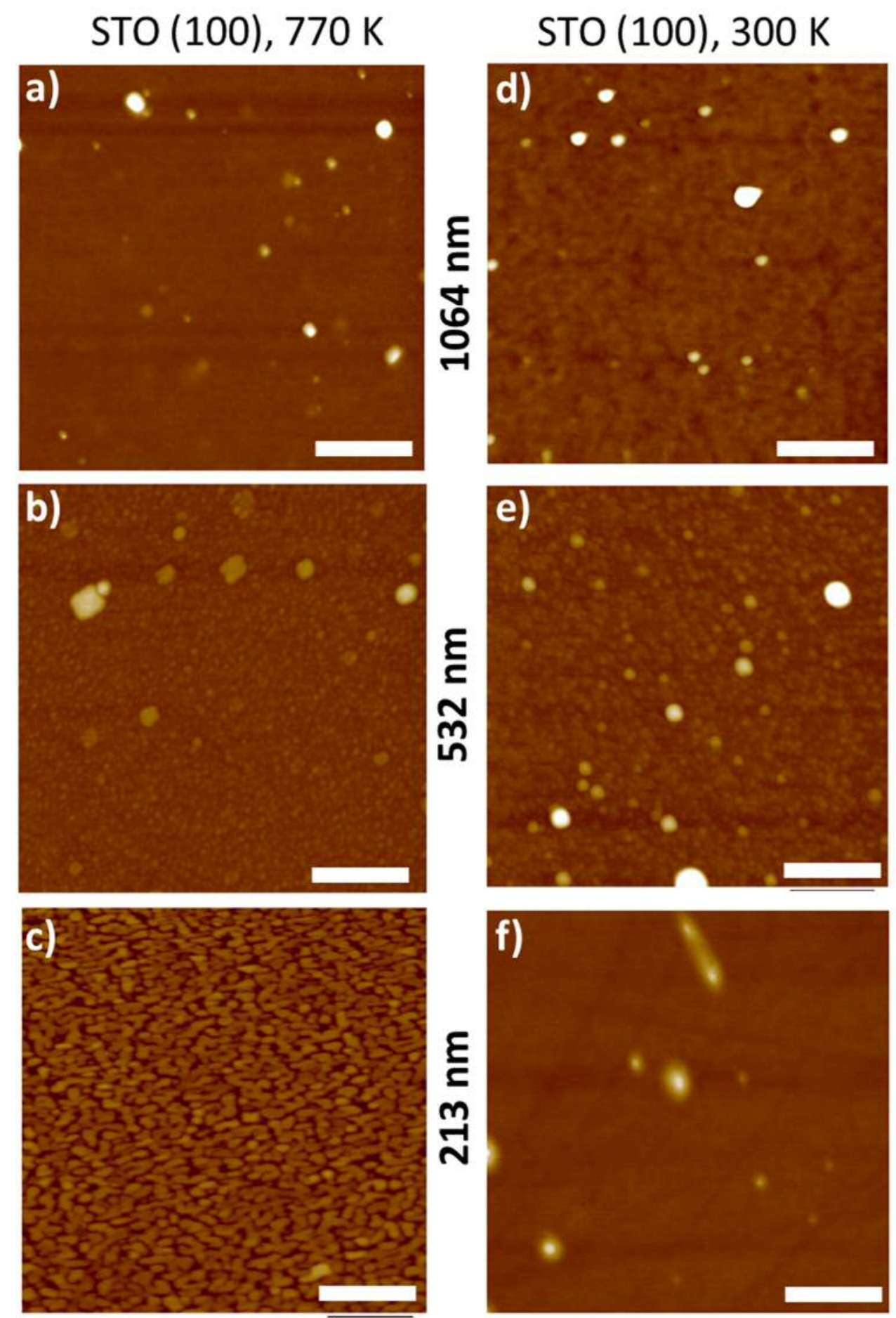
Figure 7

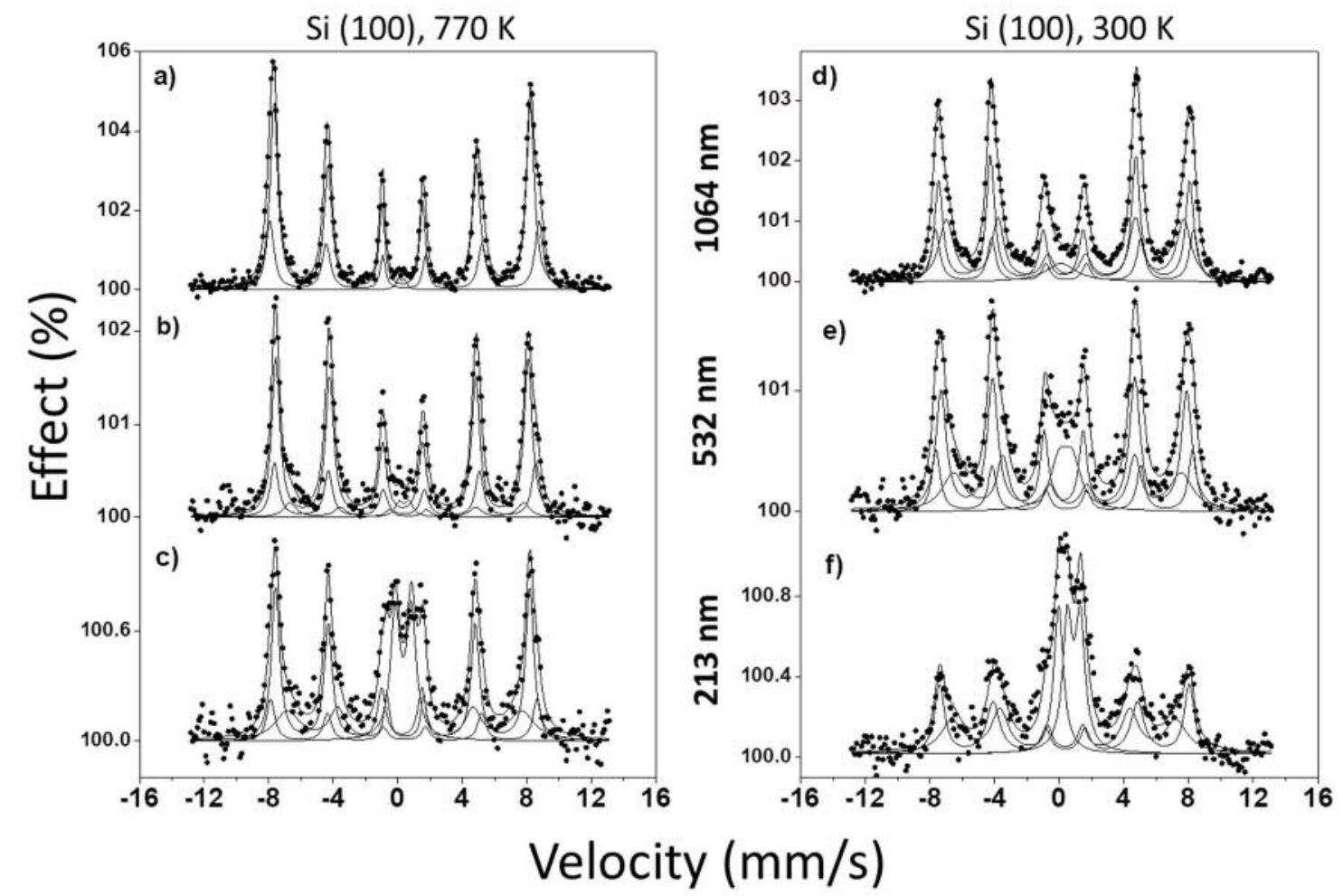


Figure 8

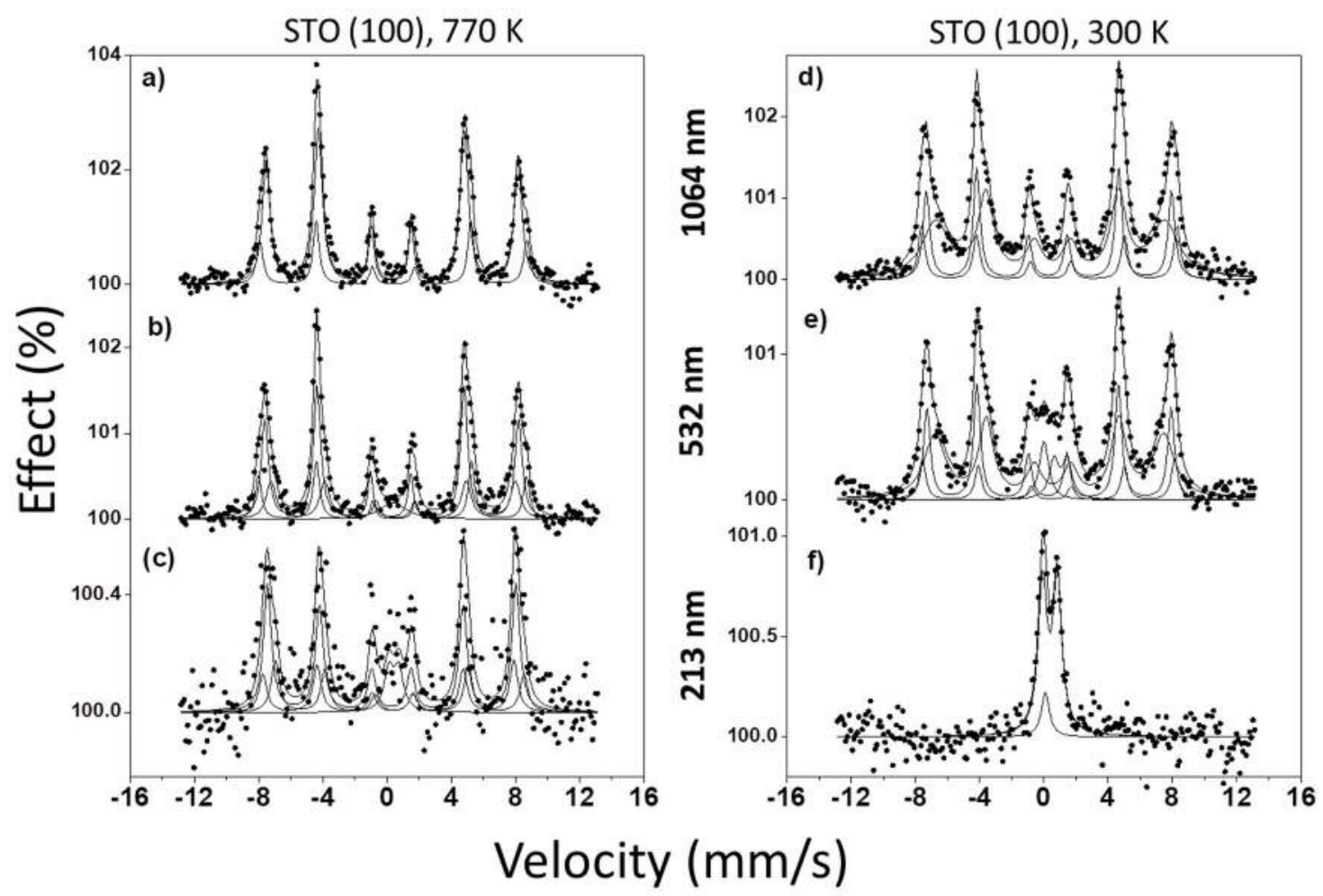


Figure 9

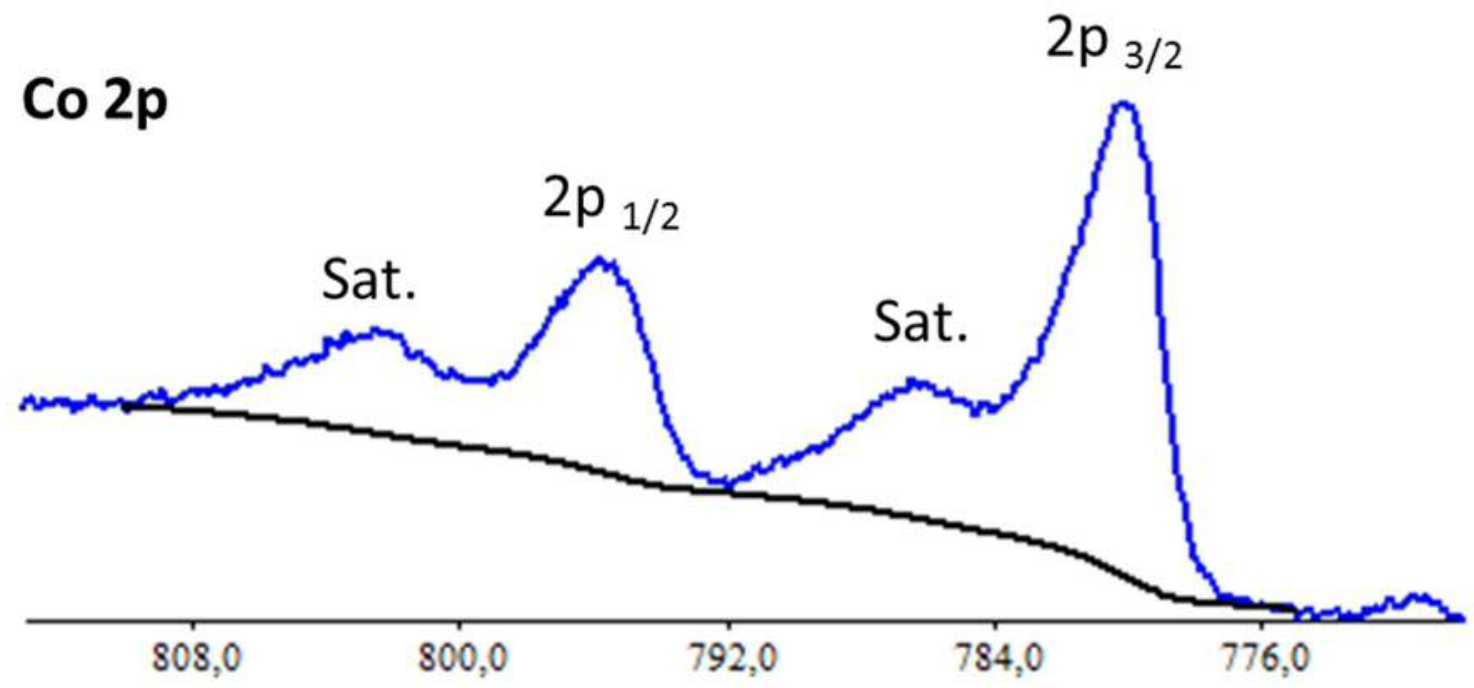

Binding Energy (eV) 
Figure 10

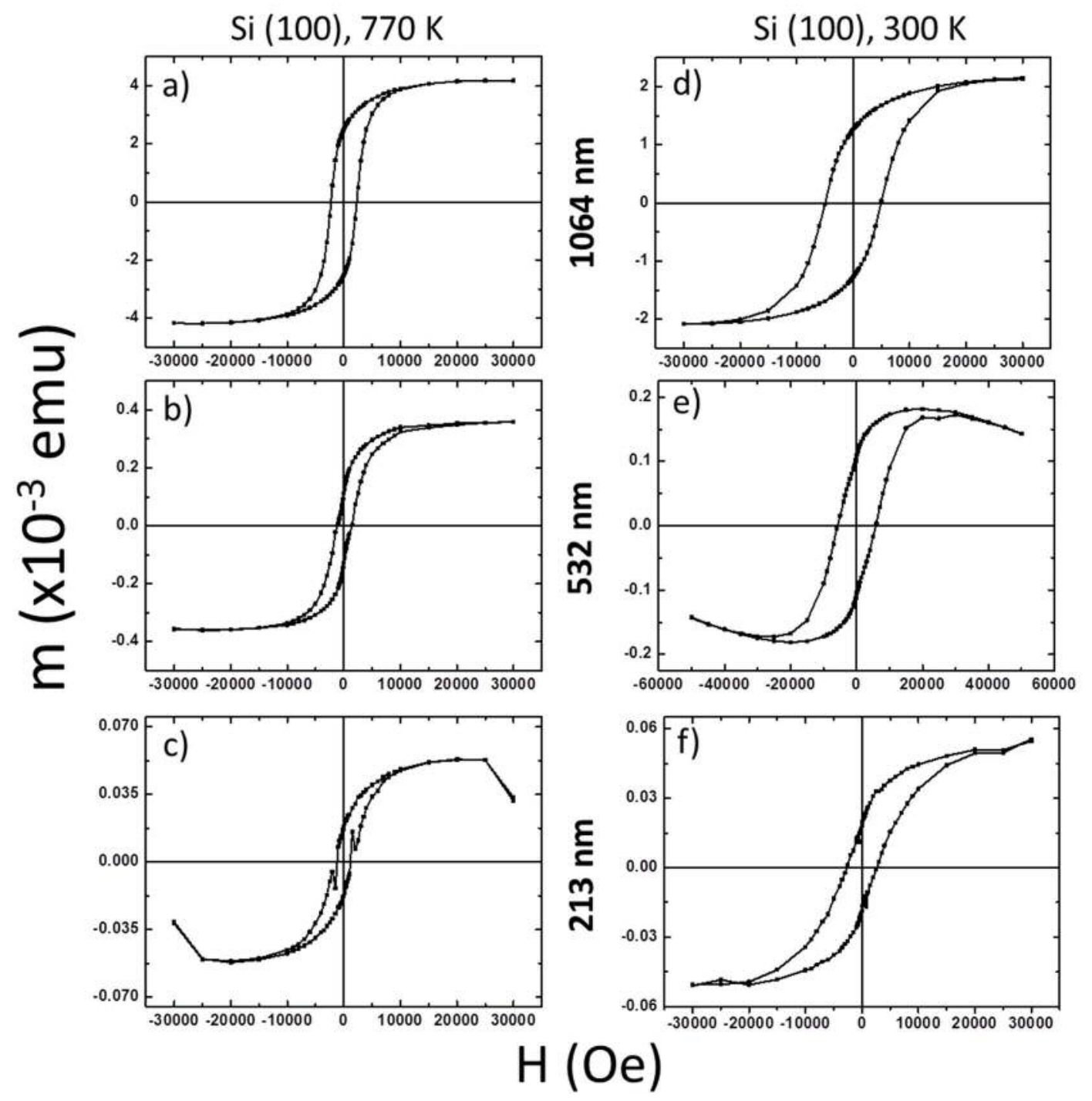


Figure 11

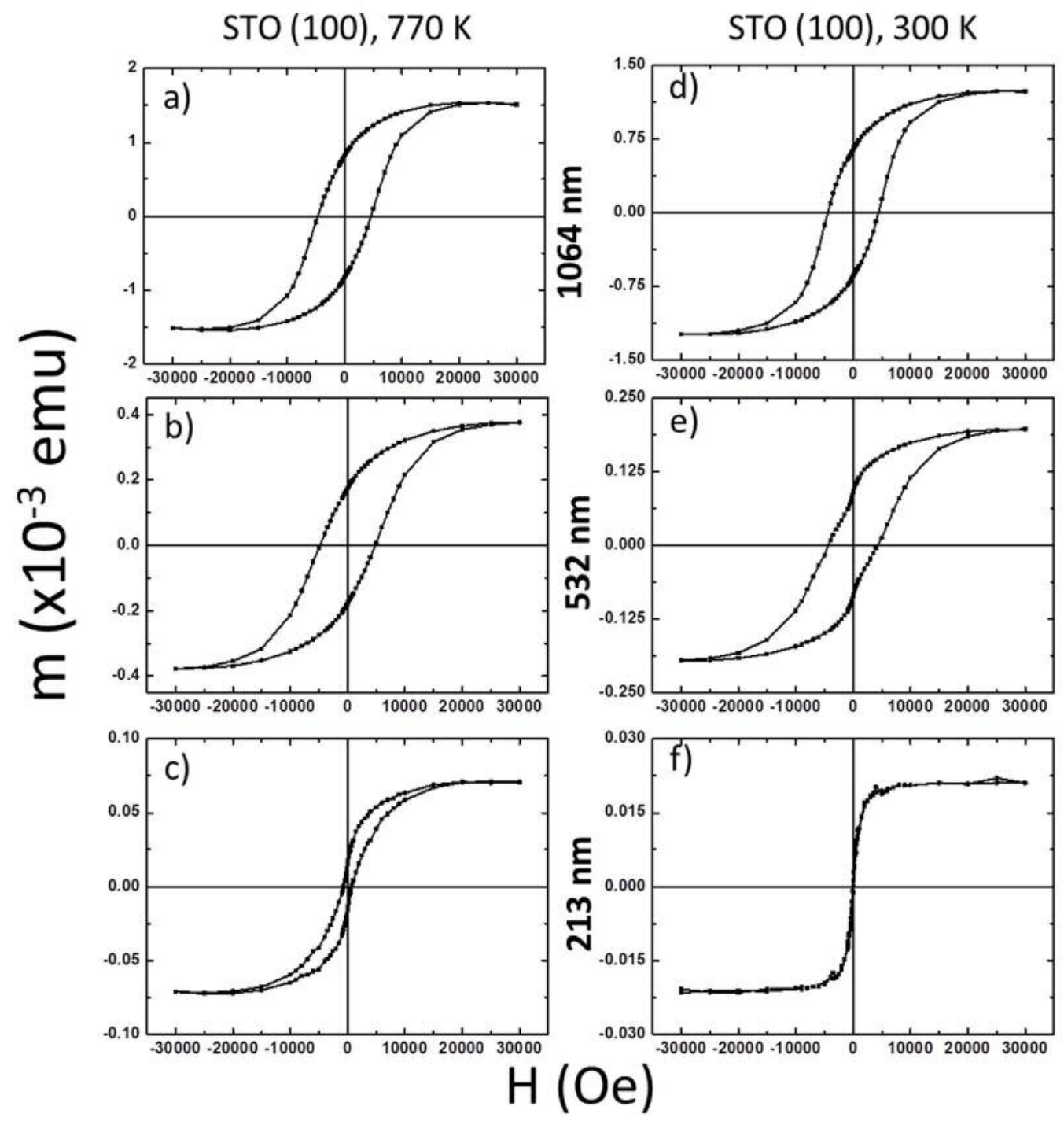


Figure 12

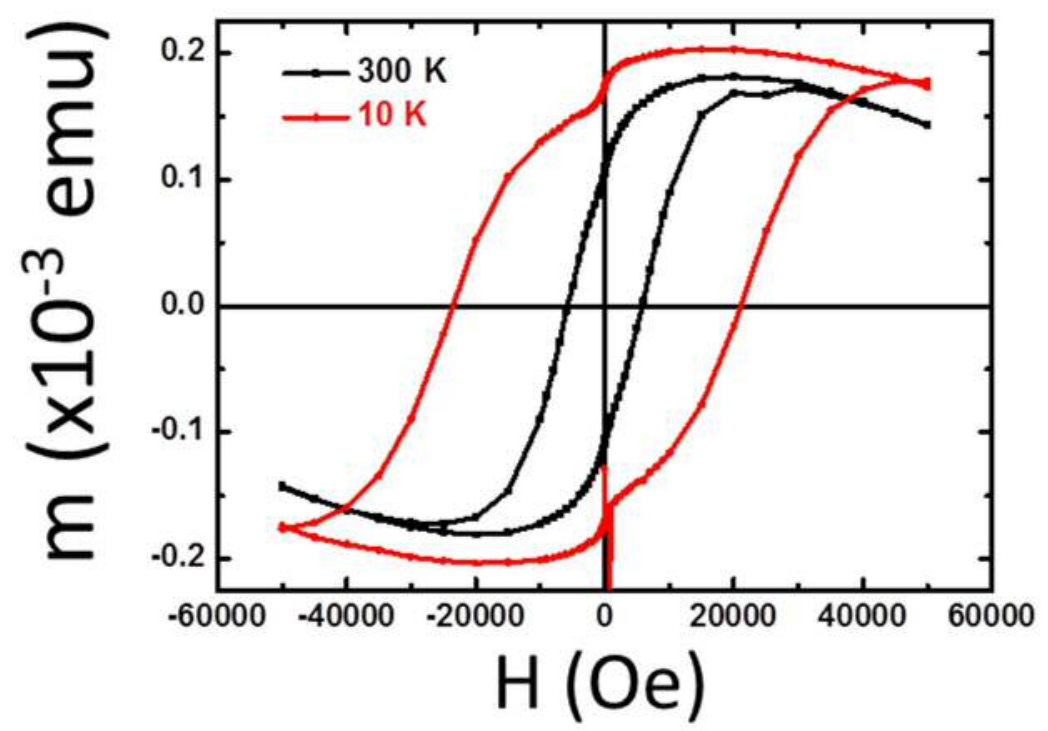

